\title{
Labor Diversity and Firm Productivity
}

\author{
Pierpaolo Parrotta* $\quad$ Dario Pozzoli ${ }^{\dagger} \quad$ Mariola Pytlikova $^{\ddagger}$
}

\begin{abstract}
Using a matched employer-employee data-set, we analyze how workforce diversity associates with the productivity of firms in Denmark, following two main econometric routes. In the first one, we estimate a standard Cobb-Douglas function, calculate the implied total factor productivity and relate the latter to diversity statistics in a second stage. This reduced-form approach allows us to identify which types of labor heterogeneity appear to descriptively matter. In the second approach, we move toward a richer production function specification, which takes different types of labor as inputs and that allows for flexible substitution patterns, and possible quality differences between types. Both methods show that workforce diversity in ethnicity is negatively associated with firm productivity. The evidence regarding diversity in education is mixed.
\end{abstract}

JEL Classification: J24, J61, J82, L20.

Keywords: Labor diversity, substitutability, complementarity, communication barriers, total factor productivity.

\footnotetext{
*Department of Economics, School of Business and Economics, Maastricht University, 6200 MD Maastricht, Netherlands. E-mail: p.parrotta@maastrichtuniversity.nl.

†The Danish Institute for Regional Government Research (KORA). Email: dapo@kora.dk.

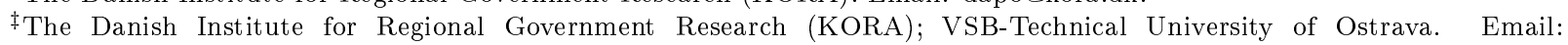
mapy@kora.dk.
} 


\section{Introduction}

Diversity in the labor force is an increasing reality in many developed countries. This diversity results from, among other things, the following major factors: policy measures that counteract population aging and antidiscrimination measures, the growth in immigration from diverse countries experienced in recent decades and the educational and skill upgrading of workforces 1 All of these factors lead to increasing diversity within the labor force in terms of age, gender, ethnicity and skills.

We observe increasing diversity across many workplaces and often hear about the importance of further internationalization and demographic diversification for firms. In many countries, firms' hiring decisions are affected by governmental affirmative action policies. Additionally, firms are under social pressure to increase diversity. At the same time, firms are challenged by the constantly changing demand for goods and services, as well as by new customers and markets, in today's globalized world. A diverse workforce may be a key factor in helping firms to understand and meet these new needs.

The popular press usually emphasizes workforce diversity as beneficial for firms, but is this really true? Do firms benefit from labor diversity and does it generate competitive advantage? What is the relationship between workplace labor diversity and firm performance? Although the issue is very important, there is considerable ambiguity surrounding this topic.

Economic theory suggests that workforce diversity may affect firm performance differently and through various channels. Diversity in skills and education may generate knowledge spillover among the employees within a firm (as long as workers' knowledge sets do not overlap and are relevant to one another), which positively affects firm performance (Lazear, 1999). However there are certain activities for which having workers with similar skills and education is preferable, as in the case of Kremer's (1993) O-ring production function, where profit-maximizing firms should match workers of similar skills/education together. Similarly, diversity in age can be beneficial to firms because the human capital of younger and older workers can complement each other. Younger employees have knowledge of new technologies and IT, and older employees have a better understanding of (and more experience with) intra-firm structures and the operating process

\footnotetext{
${ }^{1}$ Demographic projections by the United Nations suggest that during the next four decades, populations in Europe might ceteris paribus decline by $12 \%$ (United Nations, 2000). The main factor responsible for population aging is a large decline in the total fertility rate over the last half century. As a consequence of this trend, governments have adopted a number of measures to counteract the problem of population aging, including policies that encourage people to work longer, to increase female labor participation and to attract skilled immigrants. In many countries, governments have increased the regular and early retirement age, restricted access to early retirement by changing economic incentives and promoted anti-discrimination measures related to age. Female labor participation has grown in most of the world during the last century (OECD, 2005). This growth is partly due to policies encouraging women to work, e.g., better childcare and parental leave provisions and gender anti-discrimination measures. Furthermore, we can observe an increase in immigration, including to developed countries, and a broader diversity of immigrants with respect to their countries of origin (Adsera and Pytlikova, 2011; Pedersen et al. 2008). As a result of this change, the diversity of the workforce with respect to gender, age and ethnicity has increased. Finally, as a consequence of the worldwide globalization process and skill-biased technological changes, governments in many countries have taken steps to increase the skill level of the workforce (e.g., by increasing the supply of university-educated people and enhancing the availability of lifelong learning).
} 
(Lazear, 1998). However, Becker's (1957) model of co-worker discrimination suggests that demographic heterogeneity among workers may create communication friction if workers are prejudiced and may thus result in some productivity costs.

The expected contribution of ethnic and cultural diversity to firm performance is also unclear. Ethniccultural diversity may affect firm performance negatively because it may (i) hinder potential knowledge transfer among workers due to linguistic and cultural barriers, (ii) reduce peer pressure by weakening social ties and trust, and (iii) create non-pecuniary disutility associated with joining or remaining in a ethnically diverse firm (Lazear, 1999). A similar point regarding trust is made by Glaeser et al. (2000) and Alesina and La Ferrara (2002), who show that people often distrust members of other ethnic groups and tend to prefer interacting in culturally homogeneous communities. Conversely, ethnic diversity can be beneficial to firm performance, improving decision making and problem solving (Hong and Page, 2001 and 2004), stimulating the creation of new ideas and favoring knowledge transfers (Berliant and Fujita, 2008). Further, workforce diversity may provide useful information to a firm about a product market, which can enhance the firm's ability to compete in global markets (Osborne, 2000; Rauch and Casella, 2003).

To the best of our knowledge, the empirical evidence concerning diversity and economic performance is fairly scarce, and most of the previous work in this area has employed case studies of one firm (e.g., Hamilton et al. 2003, 2004; Kurtulus, 2011; Leonard and Levine, 2006) or has used aggregate regional data (e.g., Ottaviano and Peri, 2006 and 2011; Suedekum et al., 2009). The use of more comprehensive data in this field is fairly rare (Barrington and Troske, 2001; Iranzo et al. 2008; Navon, 2009; Grund and Westergaard-Nielsen, 2008, Garnero and Rycx, 2013). Furthermore, most previous studies have focused on only one dimension of diversity, with the studies by Barrington and Troske (2001), Kurtulus (2011) and Leonard and Levine (2006) being the only exceptions, and none of these studies has determined the effect of diversity on firm performance. Within this largely "explorative" and "descriptive" literature, there seems to be some consensus with respect to skill diversity as a positive factor in firm performance (Hamilton et al., 2003, 2004; Leonard and Levine, 2006; Iranzo et al. 2008; Navon, 2009; Kurtulus, 2011, Garnero and Rycx, 2013), but the evidence regarding diversity along ethnic and demographic lines is rather mixed. Case studies, for example, find that diversity with regard to age and race is negatively associated with firm performance (Hamilton et al. 2003, 2004; Leonard and Levine, 2006; Kurtulus, 2011), whereas studies using aggregated regional data find a positive correlation between ethnic diversity and performance (e.g., Ottaviano and Peri, 2006 and 2011; Alesina and La Ferrara, 2005; Sparber, 2009; Suedekum et al. 2009; Peri, 2011). As this study, Fox and Smeets (2011) make use of the Danish matched employer-employee data-set and consider different skills levels of workers. Their work is primarily focused on quality dispersion within labor rather than on the role that diversity of inputs plays in making firms more or less productive. 
In this article, we use a unique register-based linked employer-employee data-set (LEED) from Denmark, which allows us to overcome many of the limitations of previous studies and to contribute to the literature in several ways. We follow two main econometric routes to investigate the association between diversity and firm productivity. First, we estimate a standard Cobb-Douglas function, that includes labor as a single undifferentiated input, calculate the implied total factor productivity and in a second stage relate the latter to three relevant dimensions of diversity, i.e., cultural background, education and demographics, and using two alternative specifications of diversity, i.e., an aggregate and a disaggregate one. Implementing this "reduced-form" approach, we also explore the possible mechanisms through which workforce diversity affects firm productivity by attempting to test a set of hypotheses derived from existing theories. Specifically, we look at whether the impact of diversity on productivity arises from diversity within distinct occupational groups rather than the establishment's labor force in total, because we expect that diverse problem-solving abilities and creativity will be more strongly related to productivity in white-collar occupations than in blue-collar occupations. Additionally, we investigate the importance of communication costs and the costs of "cross-cultural dealing" by excluding certain groups of foreigners (i.e., individuals with tertiary education or those who speak a Germanic language) in calculating the ethnic diversity measures. The reduced-form approach allows us to identify which types of labor heterogeneity appear to descriptively matter but it does not formally take into account that the labor input is non-homogeneous in the production function, i.e., labor of different types is of different quality (Hellerstein et al., 1999; Iranzo et al., 2008; Fox and Smeets, 2011; and Irarrazabal et al., 2011). We therefore move toward a richer production function specification, which takes different types of labor as inputs and that allows for flexible substitution patterns, and possible quality differences between types. Specifically, we proceed by modeling a value-added production function that, as in the reduced-form approach, is Cobb-Douglas in capital and labor but in which the contribution of the labor aggregate also depends on different types of labor in a CES specification.

Our results generally show that labor diversity in ethnicity is negatively associated with firm productivity, while the demographic diversity seems not to matter. These findings are consistent with earlier research by Lazear (1999), Glaeser et al. (2000), Alesina and La Ferrara (2002), and may provide evidence that the negative effects of the communication and integration costs that are associated with a more demographically and culturally diverse workforce counteract the positive effects of diversity on firm productivity (i.e., the effects of creativity and knowledge spillover). The evidence regarding labor heterogeneity in terms of education is mixed instead. On the one hand, our reduced-form analysis reveals that labor diversity in education is significantly and positively associated with firm productivity. On the other hand, the estimated parameters of the structural production function, governing the substitutability between labor types, suggest that it is not generally optimal to have dispersion in labor types along the educational dimension. However estimating 
a modified specification of the structural model separately for each 2-digits industry suggests that, for about half of the sectors, skill diversity arising only among highly educated workers positively associates with firm productivity.

The structure of the article is as follows: section 2 briefly describes the data as well as the methods used to calculate labor diversity at the firm level; section 3 describes the main econometric routes we follow to measure firm productivity and its association with labor diversity. Section 4 reports results on the relationship between diversity and productivity using the reduced-form approach. Section 5 includes results from the structural production function estimation which allows for labor heterogeneity. Section 6 offers concluding remarks.

\section{Data}

\subsection{Data description}

The data-set for this empirical investigation is created by merging information from three different main sources. The first source is the Integrated Database for Labor Market Research (henceforth IDA), provided by Statistics Denmark. The IDA is a longitudinal employer-employee register that contains valuable information (age, education, other demographic characteristics, labor market experience and earnings) about each individual employed in the recorded population of Danish firms for the period 1980-2005. Only attrition due to death and permanent migration is included in the data-set. The labor market status of each person is his or her status as of the 30th of November of each year. The retrieved information is aggregated at the firm level to obtain variables such as firm size, workforce composition (including average firm tenure; shares of managers, middle managers, men, highly skilled workers, and technicians; and the shares of employees belonging to each age distribution quartile), labor diversity (see the next section for more details) partial/total foreign ownership and whether the firm is multi-establishment.

The second data source (henceforth referred to as REGNSKAB), also compiled by Statistics Denmark, provides information on firms' business accounts. These data cover the construction and manufacturing industries beginning in 1994, manufacturing beginning in 1995, wholesale trade beginning 1998 and the remaining portions of the service industry from 1999 onwards. From REGNSKAB, the following accounting items are used to estimate the production function: value added ${ }^{2}$ materials (intermediates), capital stock (fixed assets) and related industries ${ }^{3}$ Furthermore, linking these variables to a third data source, i.e., the Foreign Trade Statistics Register, we can retrieve information on whether the firm engages in export activities.

\footnotetext{
${ }^{2}$ Computed as the difference between the total sales and the intermediate costs.

${ }^{3}$ The following industries are excluded from the empirical analysis: i) agriculture, fishing and quarrying; ii) electricity, gas and water supply; and iii) public services.
} 


\subsection{Firm level labor diversity}

This section focuses on employee diversity at the firm level. Labor diversity is quantified using information regarding workers' gender, age, work experience, highest level of education achieved and nationality. We use the Herfindahl index to measure the degree of diversity at the firm level. Unlike traditional diversity measures such as the percentage of employees belonging to a specific group, the Herfindahl index combines two quantifiable measures: the "richness" (the number of categories represented within the firm or the workplace) and "equitability" or evenness (how even the numbers are for the individual categories). We calculate three separate indices to measure the cultural, skill and demographic dimensions of diversity.

Cultural diversity is represented either by the employees' nationalities or by the languages they speak. The various nationalities have been grouped into the following categories: North America and Oceania, Central and South America, Africa, West and South Europe, former Communist countries, East Asia, Other Asia, and Muslim countries ${ }^{4}$ It has been argued in the previous literature that linguistic distance serves as a good proxy for cultural distance (Guiso et al., 2009; Adsera and Pytlikova, 2011). Therefore, we have grouped employees together by the languages spoken in their countries of origin. This linguistic classification is more detailed than the grouping by nationality. We group countries (using the major official language spoken by the majority) at the third linguistic tree level, e.g., Germanic West vs. Germanic North vs. Romance languages. The information on languages is drawn from the encyclopedia of languages entitled Ethnologue: Languages of the World (Lewis, 2009); see the Appendix for more details about the list of countries and the linguistic groups included. Education-related diversity is represented by 6 categories based on information concerning the employees' highest educational level completed (tertiary education, secondary and vocational education, or pre-secondary education). We divide tertiary education into 4 categories, making a distinction between Bachelor's, Master's and postgraduate degrees in the social science, the humanities, engineering and the natural sciences. In a more disaggregated specification, we also decompose secondary education into general high school, business high school and short and long vocational education programs. Finally, the demographic index is built from the intersection of gender and age quartiles or quintiles ( 8 or 9 categories in total, depending on the level of aggregation).

To measure diversity at the firm level for each dimension, we sum the Herfindahl indices calculated for each workplace belonging to the same firm, which are weighted by the number of employees employed in each workplace:

\footnotetext{
${ }^{4}$ Second-generation immigrants are not treated as foreigners in the main analysis. However, we employ a specification in which second-generation immigrants are included in the group of foreigners in the section on the mechanisms driving the effect of workforce diversity on firm productivity.
} 


$$
\text { index }_{\text {hit }}=\sum_{w=1}^{W} \frac{N_{w}}{N_{i}}\left(1-\left(\sum_{s=1}^{S} p_{s w t}^{2}\right)\right)
$$

where index $_{h i t}$ is the Herfindahl diversity index of firm $i$ at time $t$ calculated along the $h$-th dimension (education-related and demographic), $W$ is the total number of workplaces belonging to firm $i, S$ is the total number of categories of the related diversity dimension, and $N_{w}$ and $N_{i}$ are the total number of employees of workplace $w$ and of firm $i$. The proportion of the workplace's labor force that falls into each category $s$ of the $h$-th dimension at time $t$ is represented by the term $p_{\text {swt }} 5^{5}$ The diversity index has a minimum value equal to 0 if only one category is represented within the workplace and a maximum value equal to $\left(1-\frac{1}{S}\right)$ if all categories are equally represented. The index is interpreted as the probability that two randomly drawn individuals in a workplace belong to different groups.

\subsection{Descriptive statistics}

Before discussing descriptive statistics for the variables included in the main analysis, we should stress that (a) firms with imputed accounting variables and (b) firms with fewer than 10 employees have been omitted from the main sample ${ }^{6}$ The former choice was made to reinforce the reliability of our empirical analysis. The latter was made to allow all of the investigated firms to potentially reach the highest degree of ethnic diversity when an aggregated specification is used 7 Altogether, we are able to analyze the productivity of approximately 28,000 firms for the years 1995 to 2005.

Table 1 provides basic descriptive statistics for all of the variables used in our analysis for the main sample by firm size. We split the sample into two main groups: firms above and below 50 employees. Consistent with the overall character of the Danish private sector, $78 \%$ of the observations corresponds to firms with fewer than 50 employees $8^{8}$ Compared with larger firms, smaller companies are engaged in export activities to a lesser extent and are characterized by lower levels of value added, materials and capital stock 9 Moreover,

\footnotetext{
${ }^{5}$ For ethnic diversity, the shares of foreign workers of different nationalities/linguistic groups in each workplace have been calculated as follows:

$$
p_{s w t}=\frac{\text { foreigners }_{s w t}}{\text { foreigners } s_{w t}} .
$$

${ }^{6}$ Approximately 9,000 observations corresponding to almost 2,000 firms are lost by limiting the sample to firms with at least ten employees. Descriptive statistics for the excluded firms are reported in Table A1 of Appendix 2. We have also performed the main analysis including firms with fewer than ten employees (Table A2 of Appendix 2) and we found that the results obtained from the unrestricted sample are qualitatively similar to those reported in the paper.

${ }^{7}$ When a linguistic classification is adopted, we adjust the ethnic diversity to take firm size into account. Specifically, we standardize the index for a maximum value equal to $(1-1 / \mathrm{N})$ when the total number of employees $(\mathrm{N})$ is lower than the number of linguistic groups (S).

${ }^{8}$ According to the OECD (2005), the population of Danish firms is mainly composed of small and medium-sized companies; firms with fewer than 50 employees account for $97 \%$ of firms and provide $42 \%$ of the total employment in manufacturing and services.

${ }^{9}$ Accounting values are reported in thousands of real DKK. Monetary values are deflated by using the GDP deflator for the base year 2000 retrieved from the World Bank database.
} 
whereas small firms feature larger shares of managers, relatively younger employees and personnel with secondary education, firms with more than 50 employees present larger proportions of women, foreigners and employees with longer tenure. The two groups of firms are comparable in terms of share of employees with a tertiary education, a key element in our empirical analysis, and in terms of firm ownership.

[Insert Table 1 and 2 around here]

Table 2 reports detailed descriptive statistics for all of the diversity indices by industry, by firm size and by year. As mentioned in the previous subsection, we calculate our diversity measures using two different aggregation levels for the categories included in the indices. Cultural diversity is represented by the employees' nationalities in the aggregate specification and by the languages they speak in a more disaggregate one. Education-related diversity is based on the information concerning the employees' highest educational level completed. In the aggregate index, we distinguish between different types of tertiary education while in a more disaggregate one, we also make a field-related distinction at the level of secondary education. Finally, the demographic index is based on gender and age quartiles or quintiles, depending on the level of aggregation. We observe greater diversity for firms within the manufacturing and the financial and business service industries, whereas small firms present lower diversity in all dimensions no matter the level of aggregation used. Finally, diversity is increasing slightly over time, especially in ethnicity. This result is consistent with the increasing migration to Denmark observed in recent decades.

\section{$3 \quad$ Empirical strategy}

\subsection{Productivity estimation}

As highlighted in the literature concerning the identification of the firm production function, the major issue in the estimation of input parameters is the possibility that there are factors influencing production that are unobserved by the econometrician but observed by the firm. In such a case, firms may use asymmetrically observed shocks to maximize their profits or to minimize their costs. More specifically, it is expected that firms respond to positive (negative) productivity shocks by expanding (reducing) their output, which requires a higher quantity and/or quality of production inputs. Thus, the OLS estimates of the coefficients of the inputs that are observed by econometricians may be biased and inconsistent, and error terms and regressors may be correlated. Moreover, it is widely acknowledged that whereas fixed-effects (FE) estimation techniques (Mundlak, 1961) consider firm heterogeneity, FE techniques do not solve the simultaneity problem when productivity shocks fluctuate over time. 
Several methods to address simultaneity have been proposed, such as the structural approach advocated by Olley and Pakes (1996) (OP henceforth) and Levinsohn and Petrin (2003) (LP henceforth) ${ }^{10}$ Both OP and LP suggest semiparametric methods based on (i) the identification of a proxy variable, which is assumed to be a function of time-varying productivity shocks (total factor productivity) and (ii) the definition of conditions under which this function is invertible. The aim is to infer the total factor productivity by using the observed firms' input choices (Wooldridge, 2009) ${ }^{11}$ Although OP and LP are broadly used approaches in the structural identification of the production function, they suffer from collinearity and even identification problems, as noted by Ackerberg, Caves and Frazer (2006) (henceforth ACF). Given the timing and dynamic implications of input choices, these researchers raise questions about the LP estimation techniques in particular. Therefore, ACF propose an estimation method built on OP and LP approaches that does not suffer from potential collinearity problems: the coefficient of labor is no longer estimated during the first stage (in a value added production function).

Gandhi, Navarro and Rivers (2012) (henceforth GNR) have recently expressed some concerns about the fact that the ACF approach may lead to misleading inferences, as the latter is based on the valueadded specification of the production function, which requires fairly specialized assumptions. They therefore propose an alternative method to $\mathrm{ACF}$ where the identification problem caused by flexible inputs is solved by a transformation of the firm's short run first-order condition in a gross-output specification.

\subsection{Methodological approaches}

We follow two main methodological routes to investigate the link between workforce diversity and productivity. In the first one, we estimate a standard Cobb-Douglas function, calculate the implied total factor productivity and relate the latter to our labor diversity indices in a second stage. This "reduced-form" approach allows us to evaluate which dimensions of workforce diversity seem to descriptively matter but it does not formally account for the fact that labor of different types is of different quality (Hellerstein et al., 1999; Iranzo et al., 2008; Fox and Smeets, 2011; and Irarrazabal et al., 2013). We therefore move toward

\footnotetext{
${ }^{10}$ See Ackerberg et al. (2006) for a survey.

${ }^{11}$ The approach advocated by Olley and Pakes (1996) is a two-step estimation method. In the first step, semiparametric methods are used to estimate the coefficients of the variable inputs along with the nonparametric function linking productivity to capital and investment. In the second step, parameters of capital inputs are identified based on the assumed dynamics of the productivity process (where productivity is assumed to follow a first-order Markov process, see Wooldridge, 2009). However, the OP estimation method presents two major drawbacks. First, because adjustment costs create lumpiness in the investment levels, these levels may not respond smoothly to productivity shocks. Second, the OP approach excludes firms that report zero investment levels: it induces a de facto truncation bias. To overcome these drawbacks, LP use a measure of intermediate inputs as a proxy for investment levels. This choice has many benefits. First, changes in the intermediate inputs do not typically involve adjustment costs, and the intermediate inputs therefore respond better to productivity shocks than investments. Second, the intermediate inputs provide a simple link between the estimation strategy and the economic theory because they do not typically represent state variables. Third, because intermediate inputs are almost always used in production, the LP approach circumvents the above-mentioned data truncation problem. Moreover, the LP approach suggests three specification tests for evaluating the proxy's performance (Petrin et al. 2004). However, the coefficient of the proxy is recovered during the second stage rather than the first (as in the OP approach).
} 
a richer production function specification that (i) accounts for different types of labor as inputs and (ii) adjusts for both quality differences and complementarity/substitutability between labor inputs. Specifically, we proceed by modeling a value-added production function that is Cobb-Douglas in capital and labor but in which the contribution of the labor aggregate also depends on different types of labor in a CES specification. One of main advantages of the second approach compared to the reduced-form one is that the former is more structurally motivated and theoretically grounded, as it explitly allows for flexible substitution patterns and possible quality differences between labor types. However, the structural estimation approach is computationally demanding and forces us to model labor dispersion with less flexibility and with a higher level of aggregation compared to the reduced form approach, which allows us to test a set of hypotheses and the robustness of our main results by attempting several alternative specifications as well as by looking at within occupation diversity. The reduced-form approach furthermore allows to simultaneously look at the three dimensions of diversity (ethnic, educational and demographic) within the same equation, while with the structural method we need to make the stronger assumption that each dimension of diversity enters separately into the production function. Given that both approaches have costs and benefits, we view their results as complementary.

\subsubsection{Reduced form approach: the empirical association between diversity and productivity}

Referring to the literature concerning the estimation of the production functions, we regard the method suggested by ACF as our main approach. Productivity is obtained from a Cobb-Douglas production function containing the value added, $Y$, the labor, $L$, and the capital, $K$. Because input characteristics differ across industries, the production function parameters are estimated separately for each 1-digit sector $j$. The $\log$ linear firm $i$ production function is specified as follows:

$$
\ln Y_{i j t}=\mathrm{cons}+\alpha \ln L_{i j t}+\beta \ln K_{i j t}+u_{i j t}
$$

with $t=1,2, \ldots, T$. The error term $u_{i j t}$ consists of a time-varying firm specific effect $v_{i j t}$ (unobserved by econometricians) and an idiosyncratic component $\varepsilon_{i j t}$. Following ACF, we assume that

$$
E\left(\varepsilon_{i j t} \mid l_{i j t}, k_{i j t}, m_{i j t}, l_{i j t-1}, k_{i j t-1,}, m_{i j t-1}, \ldots, l_{i j 1}, k_{i j 1}, m_{i j 1}\right)=0
$$

where $m$ refers to our proxy variable (materials) and lower-case letters to log-variables. Because past values of $\varepsilon_{i j t}$ are not included in the conditioning set, we allow for serial dependence in the pure shock term. However, we need to restrict the dynamics of the productivity process: 


$$
E\left(v_{i j t} \mid v_{i j t-1}, v_{i j t-2}, \ldots, v_{i j 1}\right)=E\left(v_{i j t} \mid v_{i j t-1}\right)=f\left(v_{i j t-1}\right)
$$

for given functions $f(\cdot)$. As in the ACF approach, we assume that the material input is selected after the labor input. As a result, material demand will be a function not only of capital and productivity but also of $l:$

$$
m_{i j t}=f\left(k_{i j t}, v_{i j t}, l_{i j t}\right)
$$

and assuming that the material demand function is strictly increasing in productivity shock $v_{i j t}$, we obtain

$$
v_{i j t}=f^{-1}\left(k_{i j t}, m_{i j t}, l_{i j t}\right)
$$

Plugging the inverse material demand into the production function, we obtain the first-stage equation, which serves here only to separate $v_{i j t}$ from $\varepsilon_{i j t}$,

$$
y_{i j t}=\text { cons }+\alpha l_{i j t}+\beta k_{i j t}+f^{-1}\left(k_{i j t}, m_{i j t}, l_{i j t}\right)+\varepsilon_{i j t} .
$$

The function $f^{-1}(\cdot)$ is proxied with a polynomial in materials, capital and labor. Therefore, the estimated net output of the idiosyncratic component is used to identify parameters for the inputs in the second stage. Recalling that $v_{i j t}$ is a first-order Markov process, we define $a_{i j t}$ as an innovation that can be correlated with the current values of the proxy variable $m_{i j t}$ and $l_{i j t}$ :

$$
a_{i j t}=v_{i j t}-g\left(v_{i j t-1}\right)
$$

where $a_{i j t}$ is mean independent of all information known at $t-1$ and $g(\cdot, \cdot)$ is also proxied with a lowdegree polynomial in the dependent variables ${ }^{12}$ Given our timing assumption, we proceed by using the moments:

$$
E\left[a_{i j t} \mid k_{i j t}, l_{i j t-1}\right]=0
$$

to identify coefficients for $k$ and $l$. Using the estimates of the production function parameters, the total factor productivity (henceforth TFP) for firm $i$ at time $t$ in industry $j$ is defined as

\footnotetext{
${ }^{12}$ To keep the number of regressors manageable, we always use a fourth-degree polynomial (with interactions) in the first stage and a third-degree polynomial in $v_{i j t}$ to compute $g($.$) .$
} 


$$
T F P_{i j t}=y_{i j t}-\alpha l_{i j t}-\beta k_{i j t}
$$

Following the computation of TFP values, the relationship between these and alternative measures of diversity can be estimated with OLS in the following equation separately for each 1-digit sector $j$ :

$$
\begin{gathered}
\text { TFP } P_{i j t}=\zeta_{0 j}+\zeta_{1 j}\left(\text { index_ethnic }_{i j t}\right)+\zeta_{2 j}\left(\text { index_edu }_{i j t}\right)+\zeta_{3 j}\left(\text { index_demo }_{i j t}\right)+ \\
+\zeta_{c j}\left(C_{i j t}\right)+\zeta_{t j}+\zeta_{r j}+\zeta_{n j}+\zeta_{n j} \star \zeta_{t j}+x_{i j t}
\end{gathered}
$$

where $\zeta_{1 j}, \zeta_{2 j}$, and $\zeta_{3 j}$ measure the associations between TFP and employees' diversity in terms of ethnicity, education and demographic characteristics, respectively; and $C_{i j t}$, is a vector including workforce composition characteristics, such as the shares of employees belonging to each category included in our diversity indices ${ }^{13}$ We think that the inclusion of such shares partly control for the fact that different labor types may have different qualities. Failing to control for labor quality, the estimated contribution of diversity in the TFP equation (10) confounds the direct effects of diversity $\left(\zeta_{1 j}, \zeta_{2 j}\right.$, and $\left.\zeta_{3 j}\right)$ with such quality differences. We further and explicitly address the issue of labor quality in the structural estimation approach described in the next sub-section. The same vector $C_{i j t}$ also include the share of managers and middle managers and average firm tenure, whether the firm is foreign-owned, whether the firm exports and a multi-establishment dummy, whereas $\zeta_{t j}, \zeta_{r j}, \zeta_{n j}$ are time, regional and two-digit industry controls, respectively.

Independent estimations of equation (10) by 1-digit industry allow us to rule out the possibility that workplace diversity only reflects an industry technology choice. Factor intensities and the mix of capital and labor may vary substantially across industries. For example, some technologies might require a set of highly skilled employees working in concert with a set of mid-level employees and a set of low-skill workers. Other technologies might only require high-skill or low-skill labor. Considering industry-specific results will therefore ensure that variations in the observed diversity of education levels across firms within the same industry will also reflect cross-firm differences in the makeup of the workforce, rather than merely reflecting which type of technology the firm has chosen ${ }^{14}$

\footnotetext{
${ }^{13}$ Specifically, in the aggregate specification of diversity we control for the shares of foreigners from North America and Oceania, Central and South America, Africa, Western and Southern Europe, former Communist countries, East Asia, Other Asia, and Muslim countries; the shares of employees with compulsory education, with secondary education, and with tertiary education split into 4 main categories (humanities, natural sciences, social sciences and engineering); and the shares of female and male employees belonging to various age distribution quartiles. In the disaggregate specification of diversity, we include the shares of foreigners belonging to each linguistic group, as described in Appendix 1, and the shares of employees with different types of education and belonging to various gender-specific age distribution quintiles, as explained in section 3.2.

${ }^{14}$ Prior academic research suggests that diversity leads to economic gains or losses depending on industry characteristics (Sparber, 2009, 2010). More specifically, diversity seems to increase productivity in sectors that require creative decision making, problem solving, and customer service, but ethnic diversity may decrease productivity in industries characterized by
} 


\subsubsection{Structural estimation approach: production function with different types of labor}

The reduced-form approach described above allows to identify which types of labor heterogeneity appear to descriptively matter but does not formally recognize that labor input is non-homogeneous, i.e., labor of different types is of different quality (Hellerstein et al., 1999; Fox and Smeets, 2011; Irarrazabal et al., 2013). Therefore we move toward a richer value-added production function, which continues to be Cobb-Douglas in capital and a labor aggregate, but the contribution of the labor aggregate also depends on different types of labor in a CES specification. To account for differences in firms' labor types, we use the observed shares of labor types within a given dimension, i.e. demographic or educational (for a similar specification see Fox and Smeets, 2011; and Irarrazabal et al., 2013). Specifically, we use the following generalized Cobb-Douglas production function in capital and labor:

$$
Y_{i j t}=A_{i j t} \cdot\left[L_{i j t} \cdot E\left(H_{1 i j t} \ldots . . H_{W i j t}\right)\right]^{\alpha} \cdot K_{i j t}^{\beta}
$$

where $W$ represents the maximum number of labor types in a given dimension and the term $E\left(H_{1 j t} \ldots . . H_{W j t}\right)$ represents the overall efficiency of the labor force of firm $i$ belonging to industry $j$ depending on the shares of these labor types $H_{w i j t} .^{15}$ Treating the overall efficiency as a CES function of the observed shares of labor types, we can express the term $E$ as:

$$
E\left(H_{1 i j t} \ldots . . H_{W i j t}\right)=\left[\left(H_{1 i j t}\right)^{\gamma}+\left(\eta_{2} H_{2 i j t}\right)^{\gamma}+\ldots .+\left(\eta_{W} H_{W i j t}\right)^{\gamma}\right]^{1 / \gamma}
$$

where the parameters $\eta_{2}, \ldots, \eta_{W}$ model the relative difference in quality between worker type $w$ and worker type 1 , i.e. if workers of type $w$ are more (less) productive than type 1 , then $\eta_{w}$ is greater (less) than one. The parameter $\gamma$ governs instead the complementarity/substitutability between labor types, as the elasticity of substitution is given by $1 /(1-\gamma)$. Assuming constant returns to each labor type, a parameter of $\gamma$ larger than one would imply that the labor types are substitutable, the isoquants are concave, the technology is submodular and exibits a taste for employing workers of different types (Grossman and Maggi 2000; Bombardini et al. 2012). Put it differently, if $\gamma$ is larger than one, then dispersion of labor types increases productivity and it is optimal to combine workers of different types along a specific dimension (Iranzo et al. 2008). By contrast, if $\gamma$ is smaller than one, there is complementarity (or imperfect substitutability) between labor types (Iranzo et al. 2008). This means that the technology is supermodular, the isoquants are convex and dispersion in labor types has a negative effect on productivity.

high levels of group work or teamwork and efficiency. Our current industry categorizations, however, are too rough for us to test the hypothesis, as jobs of both types (jobs that require creativity versus efficiency) are likely to be in each aggregate industry.

${ }^{15}$ We have to make sure that every $0<H_{\text {wijt }}<1$, as $H_{\text {wijt }}$ taking the value 0 or 1 is not consistent with the Cobb-Douglas framework. We sort this problem out by adding or subtracting a small $\epsilon$ to any $H_{w i j t}=0$ or $H_{w i j t}=1$ (Irarrazabal et al. 2013). 
As in case of the standard production function (1), we estimate equation (11) with the ACF approach. Specifically we use the current value of capital, the lagged values of labor and the shares of workers for each labor type $w$ to form a set of the following moment conditions:

$$
E\left[\tilde{a}_{i j t} \mid k_{i j t}, l_{i j t-1}, H_{1 i j t-1}, \ldots, H_{W i j t-1}\right]=0
$$

to identify coefficients for $k, l$ and the parameters $\gamma$ and $\eta_{2}, \ldots, \eta_{W}$. As in section 3.2.1, we assume that the innovation term $\tilde{a}_{i j t}$ to the productivity shock $\tilde{v}_{i j t}=f^{-1}\left(k_{i j t}, m_{i j t}, l_{i j t}, H_{1 i j t}, \ldots ., H_{W i j t}\right)$ is mean independent of all information known at $t-1$.

\section{Results from the reduced form approach}

\subsection{Main results}

As mentioned in the previous section, in the reduced form approach measures of TFP are computed as residuals from the first step estimation in which the firms' value added is regressed on their capital and labor stocks. The industry-specific elasticities of capital and labor obtained by implementing the ACF approach are reported in the first panel of Table 3. In the second and third panel of Table 3, we also report the same elasticities estimated using two alternative approaches to ACF. The first one (OP) allows for the control of sample selection issues and deals with firm exit ${ }^{16}$ The second method (GNR) employs a gross-output instead of a value-added production function. Comparing the estimated elasticities across these methods, we find that the OP and GNR estimates of the labor coefficients are more often smaller than their ACF counterparts while the capital elasticities obtained from OP (GNR) are larger (smaller). These results are generally in line with what has been found in Ackerberg, Caves and Frazer (2006) and Gandhi, Navarro and Rivers (2012).

The main results for the second step using three alternative measures of TFP (ACF, OP and GNR) are shown separately in the three panels of Table 4. As explained in section 3 , we describe the empirical association between labor heterogeneity and firm productivity, using two different aggregation levels for the categories included in our diversity indices. The results obtained using the more aggregated level are shown in the first sub-panel of each TFP panel, whereas the results obtained using the disaggregated categories are presented in the second sub-panel[17 All of the estimated coefficients of our diversity measures are reported in standard deviation units in order to compare the relative contributions of each dimension of diversity,

\footnotetext{
${ }^{16}$ We have also investigated whether firm diversity plays a role in terms of firm survival. In most industries, our diversity indices are not significantly correlated with firm probability of exiting the market. The results are reported in Table A3 of Appendix 2.

${ }^{17}$ The estimated coefficients on the share variables used as controls in the aggregate specification of diversity are reported in Table A4_1-4_3 of Appendix 2.
} 
thereby easing the comparison across magnitudes.

[Insert Table 4 around here]

Ethnic diversity is generally negatively associated with firm TFP, whereas the coefficients of educational and demographic diversity are positive. The empirical associations between educational diversity are precisely estimated in all industries but transport, whereas the coefficient of ethnic diversity is statistically significant only in the case of manufacturing, construction and wholesale trade. Demographic diversity is never significantly correlated with firm productivity. All of these results are qualitatively robust across diversity specifications and are not substantially affected by the measure of TFP employed, although the estimated correlations between ethnic diversity and productivity are slightly smaller in the both the OP and GNR specifications compared to the ACF counterpart. For the sake of brevity, we proceed by discussing the results for the manufacturing and service industries and those obtained using TFP calculated with ACF approach only. In the manufacturing sector, a standard deviation increase in ethnic diversity is associated with a decrease in firm TFP by $1.3 \%$, while a standard deviation increase in educational diversity is associated with an increase in firm TFP by $1 \%$, when an aggregated index is considered. If we focus on the disaggregated index instead, a standard deviation increase in ethnic diversity is associated with a decrease in firm TFP by $1.6 \%$, while a standard deviation increase in educational diversity is associated with an increase in firm TFP by $2.9 \%$. The magnitudes involved in the wholesale and retail trade are qualitatively similar to those estimated in the manufacturing sector.

\subsection{Testing alternative hypotheses}

In the next steps, we attempt to assess which mechanisms drive our results on employee diversity and firm TFP by exploiting the variation in occupations, nationalities and industry characteristics. While these exercises provide useful information on the channels through which diversity is associated with productivity, it is important to underline that they are not conclusive evidence of a particular mechanism. To simplify the presentation of these exercises, we discuss the results for the manufacturing and the wholesale and retail trade industry only 18 and focus on the disaggregated indices 19

First, we separately calculate the diversity indices for white- and blue-collar occupations and include them all in the same specification. We use this strategy based on the supposition that diversity could play a different role for distinct occupational groups and could consequently have varying effects on firm productivity. In particular, we expect that diverse problem-solving abilities and creativity will generate

\footnotetext{
${ }^{18}$ The results for the other industries are reported in Table A5 of Appendix 2.

${ }^{19}$ The results obtained using the aggregate indices are qualitatively similar to those obtained using the detailed categorization and are reported in Table A6 of Appendix 2.
} 
higher productivity for white-collar occupations than for blue-collar occupations 20 Second, we exclude or include certain groups of foreigners in calculating ethnic diversity to test the importance of communication costs and the costs of "cross-cultural dealing." The results regarding the association between diversity and firm productivity, calculated separately for the two occupational groups and included in the same regression are reported in the first two columns of Table 5. Our results show that the correlation of educational diversity with firm productivity is indeed much larger for white-collar occupations than for blue-collar ones. Moreover, the negative coefficient of ethnic diversity among white-collar workers is lower than the coefficient associated with blue-collar occupations. Conversely, the effect of demographic diversity is insignificant for both occupational groups ${ }^{21}$ Therefore, our results are consistent with the creativity and knowledge spillovers hypotheses proposed in the theoretical frameworks developed by Hong and Page (2001 and 2004) and Berliant and Fujita (2008).

To investigate the role of "cross-cultural dealing," we exclude either foreigners with tertiary education or foreigners who speak a Germanic language. Alternatively, we include second-generation immigrants in calculating ethnic diversity. All of these groups of foreigners are likely to absorb Danish or English (which is the communication language in many businesses in Denmark) more quickly. Therefore, it is plausible that the communication costs associated with ethnic diversity may increase (decrease) after we remove (include) these foreigners, who are likely to speak Danish or English ${ }^{22}$ The results presented in Table 5, columns 3, 4 and 5 are obtained by including both the standard ethnic diversity, as calculated in the main analysis, and an alternative one in which the second generation of immigrants is treated as non-native and where foreigners with university education or those who speak a Germanic language are included as natives, respectively. Interestingly, the coefficient of ethnic heterogeneity is larger (smaller) in absolute terms, once we exclude (include) foreigners who most likely speak Danish or English, compared to the coefficient estimated on the standard ethnic diversity ${ }^{23}$ These findings are in line with the hypothesis that the communication costs and the costs of "cross-cultural dealing" within ethnically heterogeneous workforces play a role in terms of firm productivity. However, the results obtained by excluding second generation immigrants, may also be explained by the fact that the latter generally have stronger labor market networks in addition to lower communication costs compared to other foreigners.

\section{[Insert Table 5 around here]}

\footnotetext{
${ }^{20}$ This is grounded on the fact that (i) white-collar workers typically (manage) interact with a larger number of employees than blue-collar ones; (ii) white-collar employees are, on average, more educated than employees in other occupations and are therefore more likely to access and exploit their colleagues' knowledge heterogeneity; and (iii) white-collar employees are typically more influential in firms business plans and strategies.

${ }^{21}$ Hypothesis testing also reveals that the coefficients of diversity for white-collar occupations are statistically different from the coefficients of diversity for blue-collar occupations, especially for the ethnic dimension.

${ }^{22}$ According to the existing literature, individuals have an easier time acquiring a foreign language if their mother language is linguistically closer to the foreign language (Isphording and Otten, 2011; Chiswick and Miller, 1995).

${ }^{23}$ Hypothesis testing reveals that the two estimated coefficients are significantly different from one another.
} 
We next examine the different mechanisms by which diverse workforces are associated with firm productivity by looking at different industries and firm categories ${ }^{24}$ First we do not find that the coefficients of the diversity indices differ for firms that are more open to trade 25 Therefore, our analysis does not support the hypothesis that workforce diversity provides beneficial information to firms from other countries and markets and, in this way, creates positive effects on firm productivity (Osborne, 2000; Rauch and Casella; 2003). Second, we look at whether the correlation of diversity and TFP is different for firms in high-tech industries, which tend to require higher levels of creative and problem-solving activities ${ }^{26}$ Our results reveal that the hypothesis on creativity is not supported by this empirical exercise because the coefficients of both the education and the ethnic diversity index are not statistically different across the two groups of industries, namely those with below and above average $R \& D$ intensity. Finally, we find that the positive (negative) effects of educational (ethnic) diversity are statistically stronger (weaker) in the subsample of industries with increasing employment compared to industries with declining employment. This is in line with the hypothesis that "growing" firms are more likely to benefit from diversity because they hire younger people and foreign individuals more often than do "shrinking" firms.

\subsection{Sensitivity analysis}

In the next step, as a part of our sensitivity analysis, we evaluate the variations in the coefficients estimated on labor diversity that result when diversity is computed in various ways. As in the previous sub-section, we discuss the results for the manufacturing and the wholesale and retail trade industry only and focus on the disaggregated indices 27 In particular, we use two alternative diversity indices: the Shannon-Weaver entropy index and the richness index. The entropy index is considered to be one of the most profound and useful diversity indices in biology (Maignan et al., 2003). The richness index includes a number of categories observed for each dimension of interest; it does not include the "evenness" dimension. The results are shown in Table 6, columns 1 and 2, and both sets of results are consistent with our main findings. Next, we include a Herfindhal index for the type of tertiary education (this index now has only 4 categories: engineering, natural sciences, social sciences and humanities) and the standard deviation of the years of education and age. This allows us to treat age as a cardinal variable, and to disentangle the effects associated with the amount of education from those related to the type of tertiary education. Table 6 , column 3 , reports statistically insignicant coefficients on both standard deviations and an estimate on educational diversity (the Herfindhal

\footnotetext{
${ }^{24}$ The results of these additiobnal empirical exercises are all reported in Table A7 of Appendix 2.

${ }^{25}$ Specifically we augment equation (2) by including interactions between the export dummy and diversity in ethnic, educational and demographic dimensions and we find that the interaction terms are not precisely estimated and are not jointly significantly different from zero.

${ }^{26}$ Specifically, we divide industries into two groups defined by whether their aggregate level of R\&D expenditure as a share of employment is above or below the median recorded for the overall economy.

${ }^{27}$ The results for the aggregated indices are reported in Tables A8 of Appendix 2.
} 
index for the type of tertiary education) that is in line with the finding discussed in the main analysis. These findings, together with the results obtained from occupation-specific diversity (Table 5, columns 1 and 2), may suggest that the positive association between educational diversity and firm TFP is mainly driven by the white-collar occupations, who are very likely to have tertiary education, or by workers with different types of tertiary education.

We then divide firms by size and evaluate whether there is any change in the coefficients of workforce diversity for small firms (those with fewer than 50 employees), medium-sized firms (those with 50-100 employees) and large firms (those with more than 100 employees) ${ }^{28}$ The effects of diversity could be more beneficial to larger firms because the organizational and diversity management practices of such firms are well established and formalized, and thus, they are more likely to introduce policies that can help to sustain a diversified workforce and to counteract the potential costs associated with diversity. On the one hand, the coefficients on the ethnic diversity index are negative for differently sized firms, with the largest coefficient associated with large firms, as reported in columns 4, 5 and 6 of Table 6 . On the other hand, educational diversity is more important for large than for medium-sized firms. We can therefore conclude that larger firms are more likely to benefit from educational diversity but the latter are not necessarily more successful in counteracting the costs of ethnic diversity compared to smaller firms.

Given that large cities usually host many immigrants and highly skilled workers and also house a high percentage of productive firms, we conduct an additional sensitivity check by removing the only real agglomeration area in Denmark, namely Copenhagen and its environs. The results concerning this robustness check are reported in column 7 of Table 6 and do not qualitatively differ from the main results.

Furthermore, because labor diversity has been computed at the firm level (by weighting the average of the Herfindahl indices computed at the workplace level), we evaluate how the results change if multi-establishment firms are excluded from the sample. The last column of Table 6 reports the results. These findings do not significantly differ from the main results.

\section{[Insert Table 6 around here]}

\footnotetext{
${ }^{28}$ It is important to clarify that the scope for diversity is not mechanically increasing in firm size. This can be explained with a simple example. Let's assume that there are 5 possible categories of employees, and let's compare two firms with 10 and 100 employees, respectively. The two firms would feature exactly the same level of diversity, if their workforces equally represented all possible categories, i.e. if there were 2 and 20 employees for each category in the first and second firm, respectively. For both firms the diversity index would equal $\left(1-\left((0.2)^{2} * 5\right)\right)$.
} 


\subsection{Endogeneity}

Even if it is not clear whether firms always have control over their workforce diversity ${ }^{29}$ we cannot completely rule out that firms endogenously choose the level of labor diversity in order to improve their productivity. This would imply that the findings in the previous section are likely to be biased estimates. We therefore attempt a causal effect analysis by using an instrumental variable (IV) strategy to address these potential endogeneity issues. More specifically, we instrument our diversity variables with indices of workforce diversity in cultural background, education and demographic characteristics, computed at the commuting area ${ }^{30}$ where the firm is located ${ }^{31}$ Given that diversity in a given commuting area may be a function of the current firms' demand for diversity, we predict the current composition of the labor supply at the commuting area level by using its historical composition and the current population stocks (for similarly computed instruments see Card and Di Nardo, 2000; Dustmann et al., 2005; Cortes, 2008; and Foley and Kerr, 2012). Pre-existing workforce diversity at the commuting area level may be not correlated with a firm's current labor demand and productivity, if measured with a sufficient time lag ${ }^{32}$ In particular we use workforce composition at the commuting areas from the year $1990{ }^{33}$ In this approach, for example, the instrument for ethnic diversity is calculated using the predicted share of immigrants from country $c$ and living in a commuting area $l$ at time $t, \hat{m}_{c l t}$. The latter is computed using the early 1990's stock of immigrants from country $c$ living in $l$ and its current population of immigrants at time $t$ :

\footnotetext{
${ }^{29}$ It seems reasonable to assume that the hiring and firing costs for labor or the fixed costs of changing the workforce characteristics can generally last longer than a period. This suggests that the workforce composition and diversity are very likely to be persistent over time. Therefore, firms may not promptly respond to TFP shocks with immediate changes to their diversity mix.

${ }^{30}$ The so-called functional economic regions or commuting areas are identified using a specific algorithm based on the following two criteria: firstly, a group of municipalities constitutes a commuting area if the interaction within the group of municipalities is high compared to the interaction with other areas; second, at least one municipality in the area must be a center, i.e., a certain share of the employees living in the municipality must also work in the municipality (Andersen, 2000). In total, 104 commuting areas are identified.

${ }^{31}$ Unfortunately, in our data-set, it is not possible to observe in which area each establishment of a multi-establishment firm is located. For multi-establishments firms, location information is only provided at the headquarter level. However, we do not think this represents a serious problem as multi-establishment firms constitute only $11 \%$ of our sample. This is also confirmed by the fact that estimating our IV models on the sub-sample of mono-establishment firms provide qualitatively similar results to the ones obtained from the full sample. These additional results are reported in Table A9 of Appendix 2. Note that the estimation of the parameters on diversity cannot be carried out for transport sector because of the low number of observations.

${ }^{32}$ Reverse causality however may be still an issue for big firms employing a large fraction of the local labor force. However, running our IV models on the subsample of firms with fewer than 50 employees provides qualitatively similar results to those obtained from the full sample, as shown in Table A9 of Appendix 2. Note that the estimation of the parameters on diversity cannot be carried out for transport sector because of the low number of observations.

${ }^{33}$ We choose the year 1990 as a historical base for our predictions because we believe that the lag of 5-13 years should be a sufficient lag for the purposes of our IV construction. In addition, the development in immigration to Denmark also supports the choice. The 1980s and 1990s were characterized by rather restrictive immigration policy with respect to economic migrants from countries outside the European Union (EU), which made it difficult for firms in Denmark to hire applicants from the international pool of applicants (due to the consequences of the oil crisis). Immigration to Denmark from those countries from the 1980s to the mid-1990s was characterized by immigration on the basis of humanitarian reasons and family reunion. However, since then, Denmark has further tightened its immigration policy (even laws concerning family reunification and asylum). In particular since the 2001 election, in which the right-wing Danish People's Party (DF) with its anti-immigration agenda acquired significant political power, Denmark's immigration policy became one of the strictest in the world. For firms, it meant almost zero possibilities to hire international workers from countries outside the EU, which has often been criticized by the Confederation of Danish Industry (DI). Given these historical developments, we decided to use shares of immigrants from 1990 as a base for our predictions.
} 


$$
\hat{m}_{c l t}=\frac{\text { stock }_{c l 1990}}{\sum_{c=1}^{C} \text { stock }_{c l t}}
$$

We believe that diversity at the commuting area level may represent a suitable supply driven instrument for workplace level diversity ${ }^{34}$ because commuting areas in Denmark (except for the area around Copenhagen) are typically relatively small, and are therefore very likely recruit workers from a given local supply of labor, which is characterized by a certain degree of heterogeneity. This argument is further reinforced by the role of networks in the employment process (Montgomery 1991; and Munshi, 2003). Thus, firms placed in areas with high labor diversity are also more likely to employ a more diverse workforce. It is important to emphasize that although the commuting areas are not closed economies, in the sense that workers are free to move in and out, there is clear evidence of low residential mobility (Deding et al., 2009), which seems to support the appropriateness of our IV strategy.

The results of the first and the second stage of this IV exercise are shown in Table 7 and 8 , respectively. In addition to the economic motivation for the instruments presented above, their statistical validity is largely confirmed by the F-statistics reported in Table 7.

\section{[Insert Table 7 around here]}

The estimation adopting the IV strategy yields qualitatively similar results to those reported in the main analysis (Table 4) and are in line with the conclusions drawn in the previous sub-sections. Table 8 reveals a statistically significant and positive (negative) relationship between educational (ethnic) diversity and firm productivity, especially within the manufacturing and the wholesale and retail trade sectors. However, the estimated parameters on diversity and their standard errors are generally larger compared to the results, in which diversity is treated as exogenous.

\section{[Insert Table 8 around here]}

Although our instrument is based on the historical composition of the local labor supply, however, it may still be the case that our identification strategy is invalidated by the fact that firms choose locations that are historically richer in population diversity. 36 To indirectly assess the extent to which the endogeneity

\footnotetext{
${ }^{34}$ Summary statistics of our supply driven instruments reveal that they are persistent over time, i.e. most of the variation is between commuting areas and that the overtime within variation is modest. Specifically, the overall, between, and within variations of the commuting area ethnic diversity are $0.163,0.161$, and 0.026 , respectively. The same statistics are $0.072,0.071$, and 0.012 for the commuting area educational diversity and $0.045,0.043$, and 0.01 for the commuting area demographic diversity. Similar descriptive statistics are obtained by excluding Copenhagen and its environs.

${ }^{35}$ Excluding firms located in Copenhagen and its environs from the IV estimations provides similar results to those obtained from the main sample, as shown in Table A9 of Appendix 2.

${ }^{36}$ Previous studies on firm localization (Krugman 1991, Audretsch and Feldman 1996, Adams and Jaffe 1996, Alcacer and Chung 2010, Delgado et al. 2010), however, have shown that the location choices are mainly driven by the access to local innovation potential and knowledge spillovers and also by the size of the local demand, the proximity to customers and suppliers and the quality of local physical infrastructure.
} 
of location affects our results, we have also estimated the IV models on a sub-sample of firms, for which this issue may be less important, i.e. firms which enter the market before the reference year used to predict diversity at the commuting area level (1990). Unfortunately the information about the establishment year is available only for about 30 percent of the total sample. Findings obtained from this additional robustness check are reported in Table A9 of Appendix 2 and they are qualitatively in line with those reported in Table 8 , but they are generally less precisely estimated due to the fact that the sample size considerably shrinks. Note that the estimation of the parameters on diversity cannot be carried out for construction and transport sectors because of the low number of observations.

All in all, we think that, although our IV strategy presents some potential flaws and we should interpret our IV results with caution, this additional analysis provides us with a useful tool to assess the robustness of the directions of the associations between diversity and productivity in terms of the methodology used to estimate them. Moreover, the fact that the results are qualitatively similar whether or not instruments are used, supports the initial assumption that the estimated TFP represents an exogenous first-order Markov process, i.e. these results support the assumption for the first stage of the reduce-form approach (see equations $1-8)$ to be valid.

\section{Results from the structural estimation approach}

The previous section has explored the empirical associations between labor diversity and TFP in a reducedform fashion and have served to identify which types of labor heterogeneity appear to descriptively matter. On the basis of these results, it seems that labor diversity in ethnicity and education are strongly correlated with firm productivity with opposite signs, while demographic diversity is not significantly associated with firm TFP.

While our results show that diversity in both the ethnic and the educational dimensions plays an important role, we immediately recognize that labor input is non-homogeneous (Hellerstein et al., 1999; Fox and Smeets, 2011; and Irarrazabal et al., 2011) and that dispersion in these labor types may have an impact on firm output (Iranzo et al., 2008). Therefore in this section we discuss the results obtained by estimating a richer production function specification that takes different types of labor as inputs and directly models a set of parameters adjusting for quality differences and governing complementarity/substitutability between these different labor inputs. Specifically, we show the results obtained from two alternative specifications. In the first one, we include in the overall efficiency term $E$ (see equation 12) the shares of workers belonging to each ethnic group used in the aggregate specification of our ethnic diversity index, including natives. In this case we can re-write $E$ as follows: 


$$
E\left(N_{i j t} \ldots . . F_{8 i j t}\right)=\left[\left(N_{i j t}\right)^{\gamma}+\left(\eta_{1} F_{1 i j t}\right)^{\gamma}+\ldots .+\left(\eta_{8} F_{8 i j t}\right)^{\gamma}\right]^{1 / \gamma}
$$

where $N_{i j t}$ is the share of natives, while $F_{1 i j t}, \ldots, F_{8 i j t}$ are the share of foreigners belonging to the eight categories used to construct the ethnic diversity index in the aggregate specification. Table 9 shows the estimated coefficients of the production function (11), where the overall efficiency of the labor force, $E$, is expressed by equation (15). As in the reduced form approach, production function (11) is estimated with $\mathrm{ACF}{ }^{37}$ The coefficients on labor (capital) are slightly larger (smaller) but in line with those obtained from a standard specification of the production function, as reported in Table 3. These findings are consistent with Hellerstein and Neumark (2004), who state that firms' labor heterogeneity and quality is not "a necessary component to the estimation of the rest of the production function." We also investigate how the introduction of the term $E$ in the production function affects the measurement of TFP, by comparing TFP calculated from a standard production function (see equation 9) with TFP calculated from the non-homogenous production function (11). Standard TFP estimates have a tendency to be larger than the non-standard TFP measures. This is clearly shown by plotting the kernel densities of standard and non-standard TFP measures (see Figure 1). Applying Kolmogorov-Smirnov (KS) tests confirm that the distribution of standard TFP stochastically dominates the distribution of non-standard TFP ${ }^{38}$ The fact that standard TFP may constitute an up-ward biased measure of productivity can be explained by the fact that standard TFP measures do not take into account the term $E$, which allows for flexible substitution patterns and quality differences between labor types.

The estimates of $\eta_{1}, \ldots, \eta_{W}$ parameters governing relative quality difference between native and each types of foreign workers reveal that only a few groups of foreigner workers are relatively more productive than native workers, i.e. foreign workers from West/South Europe, Other Asia and North America/Oceania. The other groups are generally less productive instead. The industry-specific estimates of the parameter $\gamma$ are precisely estimated in the wholesale and retail trade, and financial and business sector only, and are lower than one in all industries. Note that we always reject at reasonable significance levels the null hypothesis that the coefficients $\gamma$ is greater than one, implying between labor types imperfect substitutability or complementarity. This is consistent with the hypothesis that dispersion in labor types along the ethnic dimension has a negative association with firm output, in line with the results found in the previous section with the reduced form approach.

In a second specification, we categorize workers according to their education as we did in the construction

\footnotetext{
${ }^{37}$ Note that the estimation of production function (11) cannot be carried out for construction and transport sectors due to non-convergence of the estimation algorithm.

${ }^{38}$ The p-values associated with the null hypothesis for the equality of the distributions take value 0.000 in all cases.
} 
of our educational diversity index using the aggregate specification. In this case $E$ can be re-written as:

$$
E\left(C_{i j t}, S_{i j t}, T_{1 i j t}, \ldots ., T_{4 i j t}\right)=\left[\left(C_{i j t}\right)^{\gamma}+\left(\eta_{0} S_{1 i j t}\right)^{\gamma}+\left(\eta_{1} T_{1 i j t}\right)^{\gamma}+\ldots .+\left(\eta_{4} T_{4 i j t}\right)^{\gamma}\right]^{1 / \gamma}
$$

where $C_{i j t}$ is the share of workers with compulsory education, $S_{i j t}$ the share of workers with secondary education, while $T_{1 i j t}, \ldots, T_{4 i j t}$ are the share of workers with different types of tertiary education, as described in the aggregate specification of education diversity. Table 10 shows the result obtained by estimating production function (11), in which the overall efficiency of the labor force is expressed by equation (16) ${ }^{39}$ As in the previous table the coefficients on labor and capital are in line with those obtained from a standard specification of the production function, as reported in Table 3, and standard TFP estimates are larger than non standard TFP measures (see Figure 2). The $\eta$ parameters show that workers with either secondary or tertiary education are much more productive than workers with compulsory education, especially workers with an engineering or a scientific tertiary education. We find that the parameter $\gamma$ governing substitutability among employees with different educational levels is below one in all industries, suggesting a supermodular technology with a distaste for dispersion in types along the educational dimension. We therefore interpret these results as evidence that highly-educated workers and low-skilled workers are imperfect substitutes and that dispersion of labor types along the educational dimension has not a positive impact on productivity in line with what has been found in Iranzo et al. (2008).

[Insert Table 10 around here]

The latter result is starkly contradictory with the descriptive analysis reported above in section 4, where we find that our education diversity statistic is positively related with productivity. This inconsistency can be partly explained by the fact that in the descriptive analysis we do not appropriately control for quality differences between labor types, which seem to play an important role in the production function, as indicated by the estimates on the $\eta$ parameters. Furthermore in the reduced-form analysis we show that by calculating occupation-specific diversity (Table 5, columns 1 and 2) or the Herfindhal index based only on the type of tertiary education (Table 6, column 3), the positive association between educational diversity and firm TFP is largely driven by the white-collar workers, who are very likely to be highly educated, or by workers with different types of tertiary education. These results may therefore suggest that the contribution of educational diversity is most likely due to the combination of skills of highly educated employees rather than by combining the overall skills of workers with different levels of education. A possible test for the latter conjecture is to estimate a modified version of the structural production function (11), that splits labor aggregate $L$ into two

\footnotetext{
${ }^{39}$ Note that the estimation of the production function (11) cannot be carried out for construction and transport sectors due to non-convergence of the estimation algorithm.
} 
groups, i.e. employees with compulsory education $L_{1}$, and workers with more than compulsory education $L_{2}$, and that estimates the role of skill dispersion only among $L_{2}$ types. Treating $L_{1}$ as a standard Cobb-Douglas input with unit elasticity of substitution to the $L_{2}$ types, we can re-write production function (11) as follows:

$$
Y_{i j t}=A_{i j t} L_{1 i j t}^{\alpha_{1}} \cdot\left[L_{2 i j t} \cdot\left[\left(\eta_{0} S_{1 i j t}\right)^{\gamma}+\left(T_{1 i j t}\right)^{\gamma}+\left(\eta_{1} T_{2 i j t}\right)^{\gamma}+\left(\eta_{2} T_{3 i j t}\right)^{\gamma}+\left(\eta_{4} T_{4 i j t}\right)^{\gamma}\right]^{1 / \gamma}\right]^{\alpha 2} \cdot K_{i j t}^{\beta}
$$

where $S_{i j t}$ is the share of workers with secondary education, $T_{1 i j t}, \ldots ., T_{4 i j t}$ are the share of workers with different types of tertiary education, as in equation (16), and $\gamma$ governs the complementarity/substitutability only arising among workers with more than compulsory education, i.e. $L_{2}$. Table 11 shows the estimates of production function (17), using the LP approach 40 The estimates of the parameter $\gamma$ slightly increase compared to those reported in Table 10, but they never exceed the threshold of one, suggesting imperfect substitutability or complementarity also when we focus on dispersion in labor types within highly educated workers.

\section{[Insert Table 11 around here]}

A possible explanation behind the latter result may be that the industrial classification used to separately estimate production function (17) is very aggregate and may group industries with a super-modular technology together with those with a sub-modular technology under the same 1-digit industry. Estimating equation (17) separately for each 2-digits sector in fact reveals that for about half of the industries the $\gamma$ coefficient is estimated to be larger than one ${ }^{41}$ This is the case for the following industries: i) food, beverages and tobacco, ii) sales and repair of motor vehicles, iii) retail trade, iv) hotels and restaurants and v) financial intermediation. However the $\gamma$ coefficient is precisely estimated only for 3 industries (food, beverages and tobacco; sales and repair of motor vehicles; hotels and restaurants).

\section{[Insert Table 12 around here]}

By taking together all these results, we cannot thus conclude that dispersion in labor types in terms of education for the overall workforce is positively correlated with productivity. However estimating a modified specification of the structural model separately for each 2-digits industry suggests that, for about half of the sectors, skill diversity arising only among highly educated workers positively associates with firm productivity, in line with the descriptive evidence on the role of diversity among white-collar or tertiary education employees.

\footnotetext{
${ }^{40}$ Note that the estimation of production function (17) cannot be carried out with either ACF or OP due to non-convergence of the estimation algorithm.

${ }^{41}$ Note that the estimation of production function (17) cannot be carried out for textiles, other-non metallic mineral products, construction and transport due to non-convergence of the estimation algorithm.
} 


\section{Conclusions}

Using a comprehensive linked employer-employee data-set, this article primarily investigates the empirical relationship of diversity in workers' ethnic-cultural, educational and demographic characteristics with firm productivity in Denmark. Unlike the majority of previous empirical studies, which focused on single aspects of labor diversity, we provide a number of findings that extensively explore the overall consequences of firm workforce heterogeneity for firm performance. Specifically, we follow two main methodological routes to investigate the link between workforce diversity and productivity. In the first one, we estimate a standard Cobb-Douglas function, calculate the implied total factor productivity and relate the latter to our labor diversity indices in a second stage. The results from this reduced-form approach allow us to identify which types of labor heterogeneity appear to descriptively matter and suggest that labor diversity in ethnicity (education) is negatively (positively) associated with firm productivity, whereas the demographic diversity seems not to matter. Several robustness checks and the results obtained by implementing the IV method are in line with these descriptive findings. The main limit of the reduced-form approach is that it does not formally take into account that the labor input is non-homogeneous in the production function, i.e., labor of different types is of different quality (Hellerstein et al., 1999; Iranzo et al., 2008; Fox and Smeets, 2011; and Irarrazabal et al., 2011). We therefore move toward a richer production function specification, which takes different types of labor as inputs and that allows for flexible substitution patterns, and possible quality differences between types. The results obtained from this structural estimation approach suggest that labor heterogeneity in terms of ethnicity decreases firm output and that it is not optimal to have dispersion in terms of employees' education.

Thus, we find evidence that the negative effects of the communication and integration costs associated with a more culturally diverse workforce seem to counteract the positive effects of ethnic diversity (e.g., better problem-solving abilities, more creativity, and knowledge spillover). These findings are consistent with those of previous studies by Lazear (1999), Glaeser et al. (2000), and Alesina and La Ferrara (2002). Instead, the results concerning labor heterogeneity in terms of education are mixed. On the one hand, the reduced-form analysis provides descriptive evidence of a positive association between education diversity and productivity, consistently with Lazear (1999). On the other hand, the structural estimation approach reveals that the overall dispersion of labor types in terms of education decreases firm output, i.e. high-educated and low-educated workers' skills are imperfect substitutes, in line with what has been found in Iranzo et al. (2008). However estimating a modified specification of the structural model separately for each 2-digits industry suggests that, for about half of the sectors, skill diversity arising only among highly educated workers positively associates with firm productivity. 


\section{Acknowledgments}

We thank Sandra E. Black, Holger Bonin, Tor Eriksson, Luca Merlino, Andreas Moxnes, Jozef Konings, Jennifer Poole, Michael Rosholm, Fabiano Schivardi, Vanormelingen Stijn, Chad Syverson, Kenneth L. Sørensen, and Frederic Warzynski (alphabetical order) for their helpful comments and suggestions. Additionally, we appreciate the comments from participants at seminars organized by the Copenhagen Business School, University of Bergamo, Aarhus School of Business, University of Lausanne and ZEW (Mannheim) and from participants at the following conferences: ESPE 2010, the 5th Nordic Summer Institute in Labor Economics, the 2010 Ratio Young Scientist Colloquium, ESEM 2010 and CAED/COST 2010 in London. Pierpaolo Parrotta acknowledges financial support from the Graduate School for Integration, Production and Welfare, and the Swiss National Centres of Competence in Research LIVES. Mariola Pytlikova gratefully acknowledges funding from the NORFACE Migration Programme. The usual disclaimer applies. 


\section{References}

[1] Ackerberg, Daniel A., Kevin Caves, and Garth Frazer. 2006. Structural Identification of Production Functions, Department of Economics, University of California.

[2] Alcacer Juan, Wilburg Chung. 2010. Location Strategies for Agglomeration Economies. HBS Working Paper 10-071, Harvard Business School, Boston.

[3] Audretsch, David B., Maryann P. Feldman. 1996. R\&D Spillovers and the Geography of Innovation and Production. American Economic Review, 86(3): 630-40.

[4] Adams, James D., Jaffe Adam. 1996. Bounding the Effects of R\&D: An Investigation Using Linked Establishment and Firm Data. RAND Journal of Economics, 98: 673-02.

[5] Adsera, Alicia, and Mariola Pytlikova. 2011. The Role of Language in Shaping International Migration: Evidence from OECD Countries 1985-2006. Unpublished manuscript, Department of Economics, University of Aarhus.

[6] Alesina, Alberto, and Eliana La Ferrara. 2002. Who Trusts Others?. Journal of Public Economics, 85: 207-234.

[7] Alesina, Alberto, and Eliana La Ferrara. 2005. Ethnic Diversity and Economic Performance. Journal of Economic Literature, 43: 762-800.

[8] Andersen, Anne K. 2000. "Commuting Areas in Denmark." AKF Working paper.

[9] Becker, Gary. 1957. The Economics of Discrimination.Chicago, University of Chicago Press.

[10] Barrington, Linda, and Kenneth R. Troske. 2001. Workforce Diversity and Productivity: An Analysis of Employer-Employee Matched Data. Economics Program Working Papers No. 01-02.

[11] Berliant, Marcus, and Masahisa Fujita. 2008. Knowledge Creation as a Square Dance on the Hilbert Cube. International Economic Review, 49: 1251-1295.

[12] Bombardini, Matilde; Gallipoli, Giovanni and Pupato German. 2012. Unobservable Skill Dispersion and Comparative Advantage. Mimeo, University of British Columbia.

[13] Card, David, and John E. DiNardo. 2000. "Do Immigrant Inflows Lead to Native Outflows?" American Economic Review: Papers and Procedures 90: 360-67.

[14] Cortes, Patricia. 2008. "The Effect of Low-Skilled Immigration on U.S. Prices: Evidence from CPI Data." Journal of Political Economy 116 (3): 381-22. 
[15] Chiswick, Barry R., and Paul W. Miller. 1995. "The Endogeneity between Language and Earnings: International Analyses". Journal of Labor Economics, 2: 246-88.

[16] Deding, Mette, Trine Filges, and Jos Van Ommeren. 2009. "Spatial Mobility and Commuting: the Case of Two-Earner Households." Journal of Regional Science 49: 113-47

[17] Delgado Mercedes, Porter Michael E., Stern Scott. 2010. Clusters and Entrepreneurship. Journal of Economic Geography 10: 495-18.

[18] Dustmann, Christian, Francesca Fabbri, and Ian Preston. 2005. "The impact of immigration on the British labor market." Economic Journal 115(507): F324-41.

[19] Lewis, M. Paul. 2009. Ethnologue: Languages of the World, 16th edition. ISBN-13 978-1-55671-216-6. http://www.ethnologue.com/web.asp

[20] Foley, C. Fritz, and William R. Kerr. 2011. "Ethnic innovation and US multinational firm activity." National Bureau of Economic Research Working Paper 17336.

[21] Fox, Jeremy, T. and Smeets Valerie. 2011. "Does Input Quality Drive Measured Differences in Firm Productivity?", International Economic Review, vol. 52(4): 961-989.

[22] Gandhi, Amit, Navarro, Salvador and Rivers, David. 2011. "On the Identification of Production Functions: How Heterogeneous is Productivity?" University of Wisconsin-Madison and University of Western Ontario.

[23] Garnero, Andrea and Rycz, Francois. 2013. "The Heterogeneous Effects of Workforce Diversity on Productivity, Wages and Profit", IZA discussion paper No. 7350.

[24] Glaeser, Edward, David I. Laibson, Jos A. Scheinkman, and Christine L. Soutter. 2000. Measuring Trust. The Quarterly Journal of Economics, 115: 811-846.

[25] Grossman, Gene Michael and Maggi Giovanni. 2000. Diversity and Trade.American Economic Review, $1255-1275$.

[26] Grund, Christian, and Niels Westergaard-Nielsen. 2009. Age Structure of the Workforce and Firm Performance. International Journal of Manpower, 29: 410-422.

[27] Guiso, Luigi, Paolo Sapienza, and Luigi Zingales. 2009. Cultural Biases in Economic Exchange?. Quarterly Journal of Economics, 124: 1095-1131. 
[28] Hamilton, Barton H., Jack A. Nickerson, and Hideo Owan. 2003. Team Incentives and Worker Heterogeneity: An Empirical Analysis of the Impact of Teams on Productivity and Participation. Journal of Political Economy, 111: 465-497.

[29] Hamilton, Barton H., Jack A. Nickerson, and Hideo Owan. 2004. Diversity and Productivity in Production Teams. Unpublished manuscript, Department of Economics, Washington University in St. Louis.

[30] Hellerstein, Judith and David Neumark. 2004. "Production Function and Wage Equation Estimation with Heterogeneous Labor: Evidence from a New Matched Employer-Employee Data Set", NBER Working Paper 10325 .

[31] Hong, Lu, and Scott E. Page. 2001. Problem Solving by Heterogeneous Agents. Journal of Economic Theory, 97: 123-163.

[32] Hong, Lu, and Scott E. Page. 2004. Groups of Diverse Problem Solvers Can Outperform Groups of High-Ability Problem Solvers. Proceedings of the National Academy of Sciences, 101: 123-139.

[33] Iranzo, Susana, Fabiano Schivardi, and Elisa Tosetti. 2008. Skill Dispersion and Firm Productivity: An Analysis with Employer-Employee Matched Data. Journal of Labor Economics, 26: 247-285.

[34] Irarrazabal, Alfonso, Moxnes, Andreas and Ulltveit-Moe, Karen, H. Forthcoming. Heterogeneous Firms or Heterogeneous Workers? Implications for Export Premia and the Gains from Trade", Review of Economic Studies.

[35] Isphording, Ingo E., and Sebastian Otten. 2011. Linguistic Distance and the Language Fluency of Immigrants, Ruhr Economic Papers No. 274.

[36] Kurtulus, Ana F. 2011. What Types of Diversity Benefit Workers? Empirical Evidence on the Effects of Co-Worker Dissimilarity on the Performance of Employees. Industrial Relations: A Journal of Economy and Society, 50: 678-712.

[37] Kremer, Michael. 1993. The O-Ring Theory of Economic Development. Quarterly Journal of Economics, 108: 551-75.

[38] Krugman, Paul. 1991. Geography and Trade. MIT Press, Cambridge MA.

[39] Lazear, Edward P. 1998. Personnel Economics for Managers. New York, John Wiley \& Sons

[40] Lazear, Edward P. 1999. Globalisation and the Market for Team-Mates. The Economic Journal, 109: $15-40$. 
[41] Leonard, Jonathan S., and David I. Levine. 2006. Diversity, Discrimination, and Performance. Institute for Research and Employment Working Paper, No 147.

[42] Levinsohn, James, and Amil Petrin. 2003. Estimating Production Functions using Inputs to Control for Unobservables. Review of Economic Studies, 70: 317-341.

[43] Maignan, Carole, Gianmarco Ottaviano, Dino Pinelli and Francesco Rullani. 2003. Bio-Ecological Diversity vs. Socio-Economic Diversity: A Comparison of Existing Measures. Nota di Lavoro, Fondazione Eni Enrico Mattei.

[44] Montgomery, James D. 1991. "Social Networks and Labor Market Outcomes: Toward an Economic Analysis." American Economic Review 81: 1408-18.

[45] Mundlak, Yair. 1961. Empirical Production Function Free of Management Bias. Journal of Farm Economics, 43: 44-56.

[46] Munshi, Kaivan. 2003. "Networks in the Modern Economy: Mexican Migrants in the US Labor Market." The Quarterly Journal of Economics 118: 549-99.

[47] Navon, Guy. 2009. Human Capital Spillovers in the Workplace: labor Diversity and Productivity. MPRA Paper No. 17741.

[48] OECD. 2005. Economic Survey of Denmark. Paris, 2005. Labor Research, 21: 463-475.

[49] Olley, G. Steven and Ariel Pakes. 1996. The Dynamics Of Productivity In The Telecommunications Equipment Industry. Econometrica, 64: 1263-1297.

[50] Osborne, E. 2000. The Deceptively Simple Economics of Workplace Diversity. Journal of Labor Research 21: $463-75$.

[51] Ottaviano, Gianmarco I. P. and Giovanni Peri. 2006. The Economic Value of Cultural Diversity: Evidence from US Cities. Journal of Economic Geography, 6: 9-44.

[52] Ottaviano, Gianmarco I. P., and Giovanni Peri. 2011. Rethinking the Effects of Immigration on Wages. Journal of European Economic Association. doi: 10.1111/j.1542-4774.2011.01052.

[53] Pedersen, Peder J., Mariola Pytlikova, and Nina Smith. 2008. Selection and Network Effects - Migration Flows into OECD Countries 1990-2000. European Economic Review, 52: 1160-1186.

[54] Peri Giovanni. 2011. The Effect of Immigration on Productivity: Evidence from U.S. States. The Review of Economics and Statistics (forthcoming). 
[55] Petrin, Amil, James Levinsohn, and Brian Poi. 2003. Production Function Estimation in Stata Using Inputs to Control for Unobservables. Stata Journal, 4: 113-123.

[56] Rauch, James E., and Alessandra Casella. 2003. Overcoming Informational Barriers to International Resource Allocation: Prices and Ties. Economic Journal, 113: 21-42.

[57] Sparber, Chad. 2009. Racial Diversity and Aggregate Productivity in US Industries: 1980-2000. Southern Economic Journal, 75: 829-856.

[58] Sparber, Chad. 2010. Racial Diversity and Macroeconomic Productivity across US States and Cities. Regional Studies, 44: 71-85.

[59] Suedekum, Jens, Katja Wolf and Uwe Blien. 2009. Cultural Diversity and Local Labor Markets. IZA Discussion Paper No. 4619.

[60] Wooldridge, Jeffrey Marc. 2009. On estimating firm-level production functions using proxy variables to control for unobservables. Economics Letters, 104: 112-114.

[61] United Nations. 2000. Replacement Migration: Is it a Solution to Declining and Aging Populations?, New York, UN Population Division. Department of Economic and Social Affairs, 2000. 


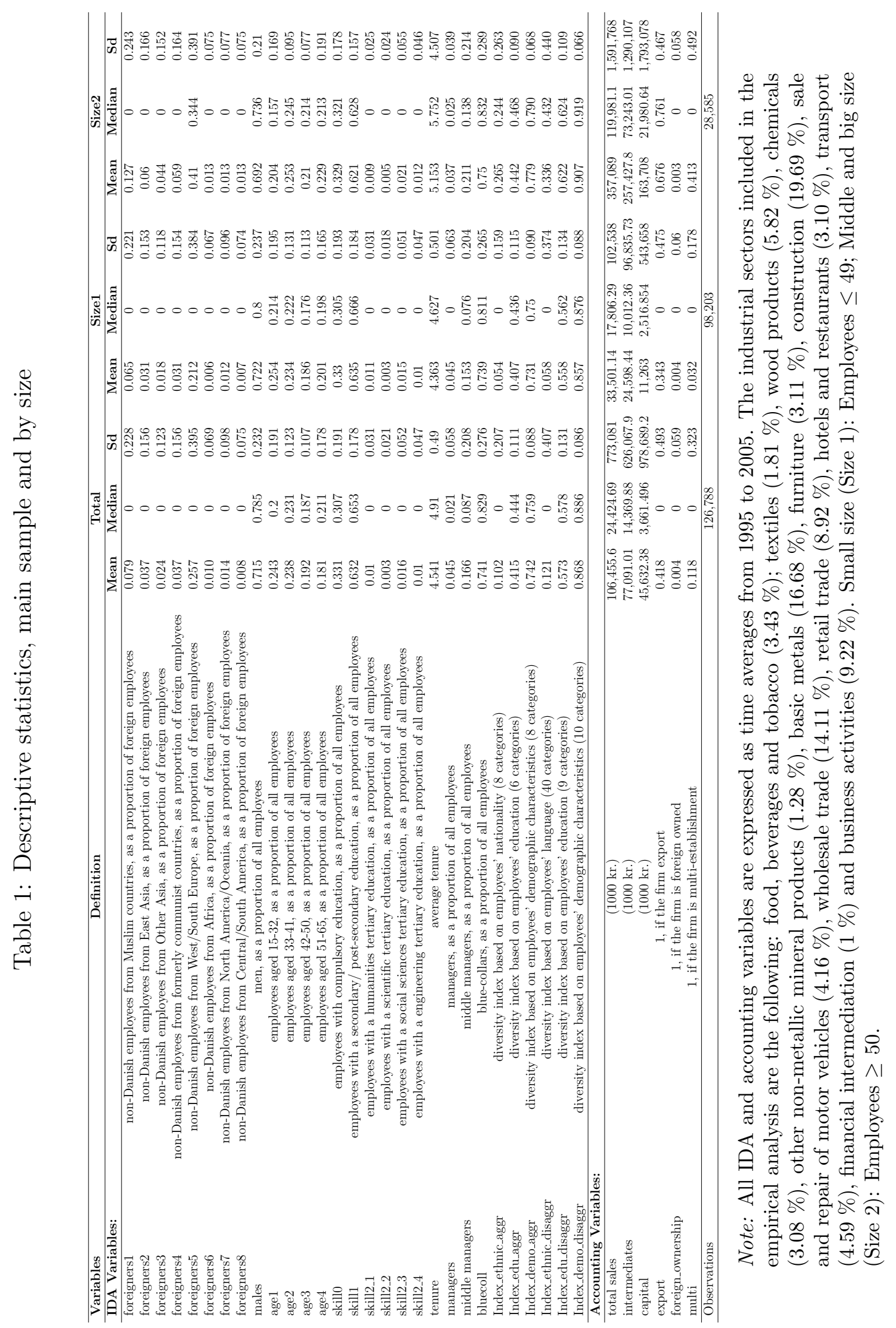


Table 2: Descriptive statistics of diversity indices by industry, by size and by year

\begin{tabular}{|c|c|c|c|c|c|}
\hline & \multicolumn{5}{|c|}{ Aggregate specification } \\
\hline & Manufacturing & Construction & Wholesale and retail trade & Transport & Financial and business services \\
\hline Index ethnic & 0.154 & 0.031 & 0.077 & 0.080 & 0.138 \\
\hline Index edu & 0.430 & 0.387 & 0.402 & 0.437 & 0.449 \\
\hline Index demo & 0.766 & 0.716 & 0.730 & 0.738 & 0.751 \\
\hline \multirow[t]{2}{*}{ Observations } & 45,766 & 24,605 & 37,991 & 5,841 & 12,667 \\
\hline & Small size & Middle size & Big size & 1995 & 2005 \\
\hline Index ethnic & 0.030 & 0.080 & 0.259 & 0.081 & 0.121 \\
\hline Index edu & 0.399 & 0.417 & 0.441 & 0.427 & 0.414 \\
\hline Index demo & 0.717 & 0.747 & 0.777 & 0.735 & 0.739 \\
\hline \multirow[t]{3}{*}{ Observations } & 50,564 & 46,630 & 29,676 & 7,461 & 13,819 \\
\hline & \multicolumn{5}{|c|}{ Disaggregate specification } \\
\hline & Manufacturing & Construction & Wholesale and retail trade & Transport & Financial and business services \\
\hline Index ethnic & 0.191 & 0.046 & 0.080 & 0.083 & 0.156 \\
\hline Index edu & 0.578 & 0.503 & 0.573 & 0.567 & 0.698 \\
\hline Index demo & 0.891 & 0.847 & 0.854 & 0.865 & 0.877 \\
\hline \multirow[t]{2}{*}{ Observations } & 45766 & 24605 & 37991 & 5841 & 12667 \\
\hline & Small size & Middle size & Big size & 1995 & 2005 \\
\hline Index ethnic & 0.028 & 0.090 & 0.328 & 0.081 & 0.137 \\
\hline Index edu & 0.545 & 0.573 & 0.622 & 0.546 & 0.588 \\
\hline Index demo & 0.841 & 0.876 & 0.906 & 0.862 & 0.866 \\
\hline Observations & 50,564 & 46,630 & 29,676 & 7,461 & 13,819 \\
\hline
\end{tabular}

Note: Small size: Employees $\leq 49$; Middle size: $50 \leq$ Employees $\leq$ 99; Big size: Employees $\geq 100$. 


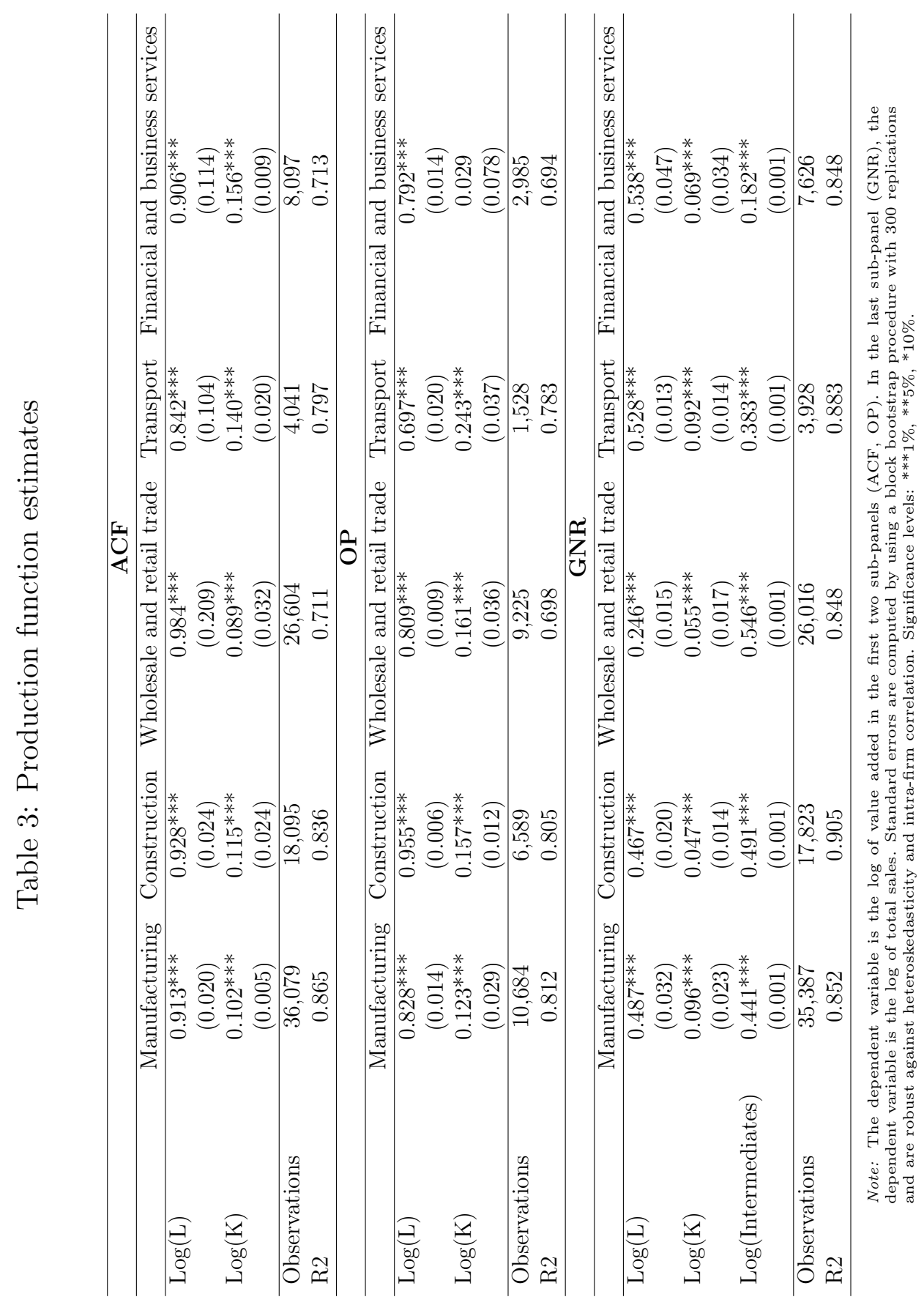




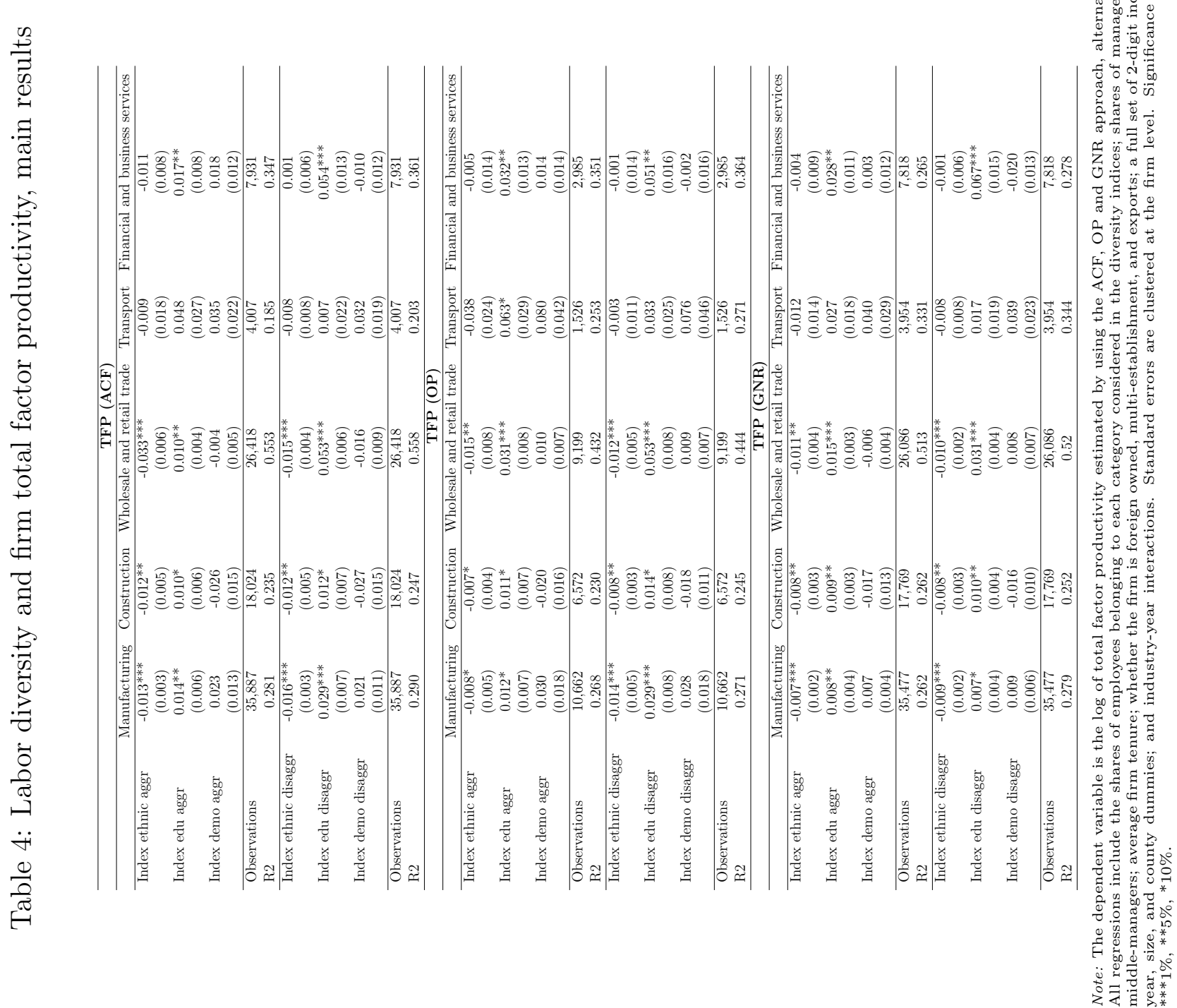




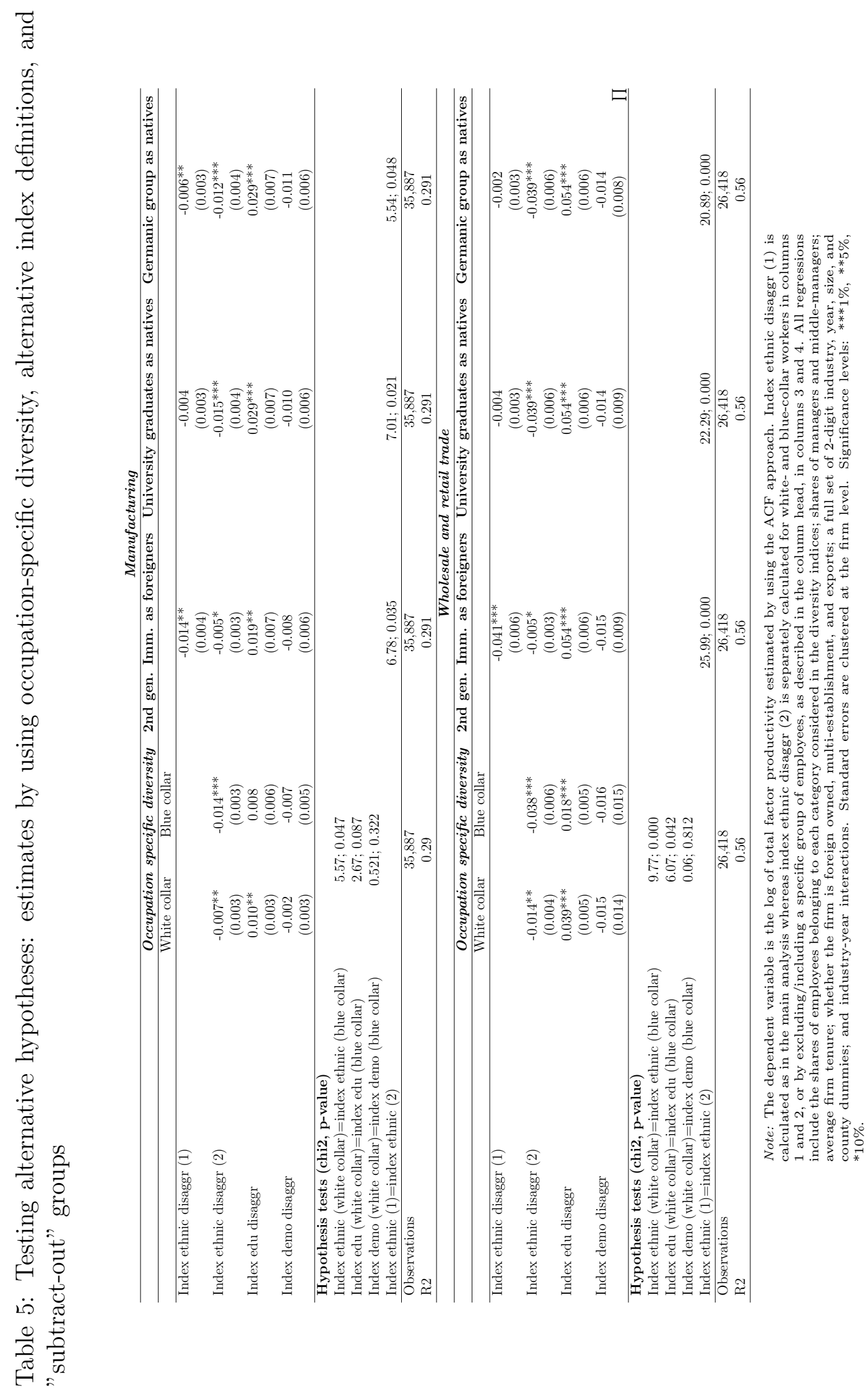




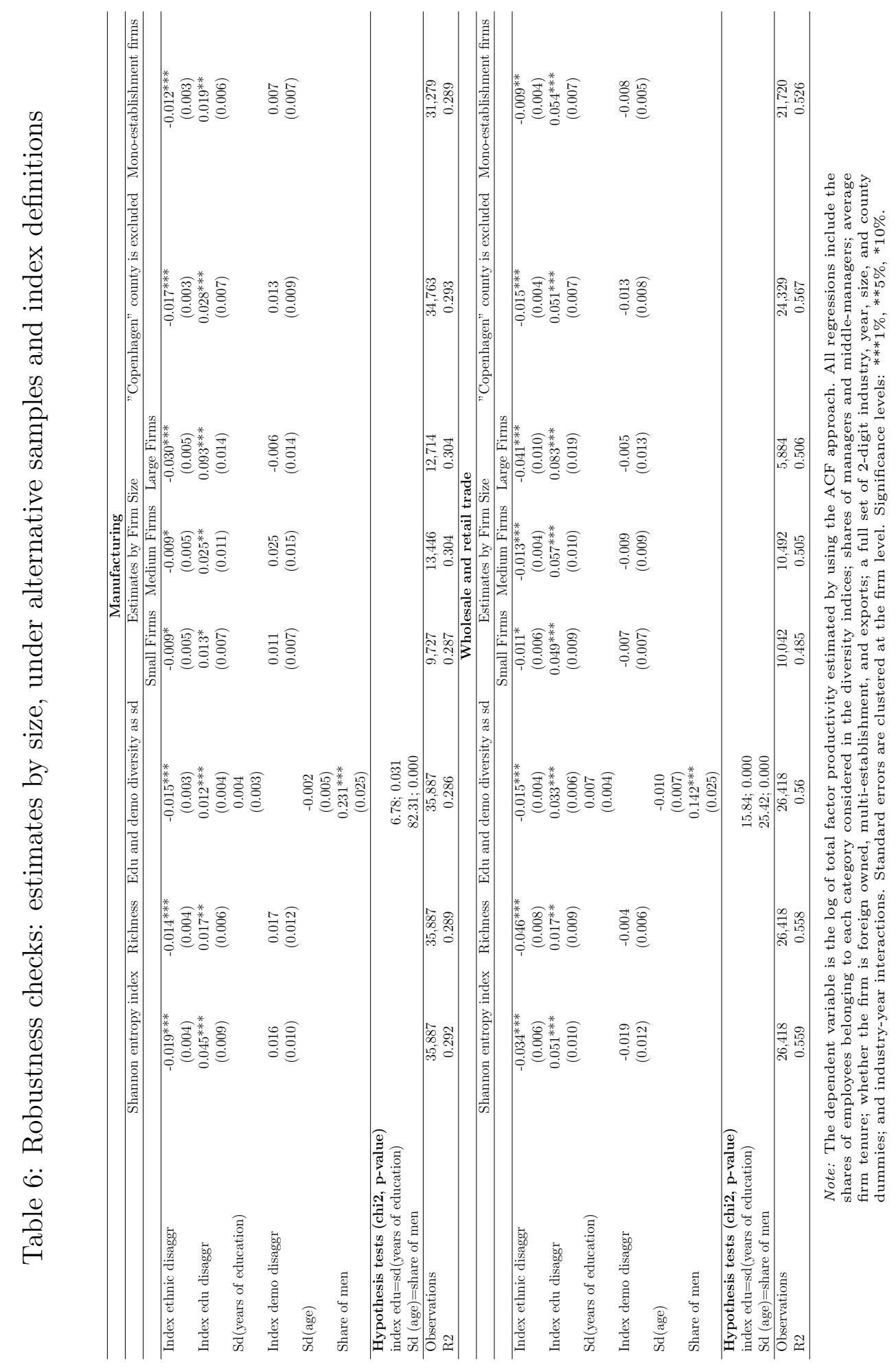


Table 7: IV results: first stage regressions

\begin{tabular}{|c|c|c|c|}
\hline & \multicolumn{3}{|c|}{ Manufacturing } \\
\hline & Index ethnic disaggr & Index edu disaggr & Index demo disaggr \\
\hline \multirow[t]{2}{*}{ index ethnic com } & $1.601^{* * *}$ & $-0.120^{* *}$ & $-0.056^{* *}$ \\
\hline & $(0.177)$ & $(0.051)$ & $(0.028)$ \\
\hline \multirow[t]{2}{*}{ index edu com } & $-0.884^{* * *}$ & $0.273^{* * *}$ & $-0.190^{* * *}$ \\
\hline & $(0.234)$ & $(0.066)$ & $(0.051)$ \\
\hline \multirow[t]{2}{*}{ index demo com } & $-2.134^{* * *}$ & -0.039 & $1.009^{* * *}$ \\
\hline & $(0.342)$ & $(0.196)$ & $(0.097)$ \\
\hline F test (excluded instruments); p-value & $36.83 ; 0.000$ & $18.14 ; 0.000$ & $29.44 ; 0.000$ \\
\hline Observations & 48,238 & 48,238 & 48,238 \\
\hline \multirow[t]{3}{*}{$\mathrm{R} 2$} & 0.227 & 0.594 & 0.385 \\
\hline & \multicolumn{3}{|c|}{ Construction } \\
\hline & Index ethnic disaggr & Index edu disaggr & Index demo disaggr \\
\hline \multirow[t]{2}{*}{ index ethnic com } & $0.351^{* * *}$ & $-0.243^{* * *}$ & -0.038 \\
\hline & $(0.082)$ & $(0.062)$ & $(0.030)$ \\
\hline \multirow[t]{2}{*}{ index edu com } & $0.336^{* *}$ & $0.314^{* * *}$ & -0.035 \\
\hline & $(0.113)$ & $(0.077)$ & $(0.060)$ \\
\hline \multirow[t]{2}{*}{ index demo com } & -0.494 & $0.542^{* *}$ & $0.585^{* *}$ \\
\hline & $(0.327)$ & $(0.173)$ & $(0.173)$ \\
\hline F test (excluded instruments); p-value & $26.69 ; 0.000$ & $38.90 ; 0.000$ & $6.08 ; 0.011$ \\
\hline Observations & 26,969 & 26,969 & 26,969 \\
\hline \multirow[t]{3}{*}{$\mathrm{R} 2$} & 0.131 & 0.574 & 0.348 \\
\hline & \multicolumn{3}{|c|}{ Wholesale and retail trade } \\
\hline & Index ethnic disaggr & Index edu disaggr & Index demo disaggr \\
\hline \multirow[t]{2}{*}{ index ethnic com } & $0.909^{* * *}$ & $-0.342^{* * *}$ & $0.166^{* * *}$ \\
\hline & $(0.112)$ & $(0.060)$ & $(0.046)$ \\
\hline \multirow[t]{2}{*}{ index edu com } & $0.431^{* *}$ & $0.938^{* * *}$ & $-0.496^{* * *}$ \\
\hline & $(0.135)$ & $(0.102)$ & $(0.057)$ \\
\hline \multirow[t]{2}{*}{ index demo com } & -0.192 & $-0.256^{* *}$ & $1.238^{* * *}$ \\
\hline & $(0.195)$ & $(0.078)$ & $(0.086)$ \\
\hline F test (excluded instruments); p-value & $19.77 ; 0.000$ & $37.81 ; 0.000$ & $90.43 ; 0.000$ \\
\hline Observations & 41,493 & 41,493 & 41,493 \\
\hline \multirow[t]{3}{*}{$\mathrm{R} 2$} & 0.187 & 0.570 & 0.481 \\
\hline & \multicolumn{3}{|c|}{ Transport } \\
\hline & Index ethnic disaggr & Index edu disaggr & Index demo disaggr \\
\hline \multirow[t]{2}{*}{ index ethnic com } & $0.212^{* * *}$ & 0.022 & $-0.187^{* *}$ \\
\hline & $(0.023)$ & $(0.236)$ & $(0.062)$ \\
\hline \multirow[t]{2}{*}{ index edu com } & 0.510 & $0.017^{* *}$ & 0.158 \\
\hline & $(0.486)$ & $(0.008)$ & $(0.126)$ \\
\hline \multirow[t]{2}{*}{ index demo com } & -0.389 & 0.202 & $0.576^{* *}$ \\
\hline & $(2.076)$ & $(0.280)$ & $(0.245)$ \\
\hline F test (excluded instruments); p-value & $16.70 ; 0.000$ & $9.89 ; 0.000$ & $25.78 ; 0.000$ \\
\hline Observations & 6,287 & 6,287 & 6,287 \\
\hline \multirow[t]{3}{*}{$\mathrm{R} 2$} & 0.261 & 0.635 & 0.285 \\
\hline & Financ & al and business $\mathrm{s}$ & ervices \\
\hline & Index ethnic disaggr & Index edu disaggr & Index demo disaggr \\
\hline index ethnic com & $1.585^{* * *}$ & $-0.407^{* * *}$ & -0.076 \\
\hline & $(0.230)$ & $(0.081)$ & $(0.058)$ \\
\hline index edu com & -0.021 & $0.903^{* * *}$ & 0.080 \\
\hline & $(0.224)$ & $(0.074)$ & $(0.063)$ \\
\hline index demo com & -0.319 & -0.225 & $1.027^{* * *}$ \\
\hline & $(0.366)$ & $(0.206)$ & $(0.097)$ \\
\hline F test (excluded instruments); p-value & $16.81 ; 0.000$ & $37.02 ; 0.000$ & $25.87 ; 0.000$ \\
\hline Observations & 14,008 & 14,008 & 14,008 \\
\hline R2 & 0.396 & 0.468 & 0.353 \\
\hline
\end{tabular}

Note: The dependent variable is diversity at the firm level. All regressions include the shares of employees belonging to each category considered in the diversity indices; shares of managers and middle-managers; average firm tenure; whether the firm is foreign owned, multi-establing

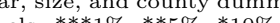
等 
Table 8: Labor diversity and productivity, IV results: second stage regressions

\begin{tabular}{lccccc}
\hline & Manufacturing & Construction & Wholesale and retail trade & Transport & Financial and business services \\
\hline index ethnic disaggr & $-0.026^{*}$ & $-0.038^{*}$ & $-0.028^{* *}$ & -0.031 & 0.009 \\
& $(0.014)$ & $(0.019)$ & $(0.014)$ & $(0.084)$ & $(0.012)$ \\
index edu disaggr & $0.061^{* *}$ & 0.037 & $0.095^{* *}$ & 0.047 & $(0.149)$ \\
index demo disaggr & $(0.028)$ & $(0.019)$ & $-0.040)$ & -0.085 & $(0.038)$ \\
& 0.093 & $(0.049)$ & $(0.033)$ & $(0.070)$ & -0.048 \\
Observations & $(0.086)$ & 18,024 & 26,418 & 4,007 & $(0.033)$ \\
R2 & 35,887 & 0.123 & 0.252 & 0.189 & 7,931 \\
\hline
\end{tabular}

Note: The dependent variable is the log of total factor productivity estimated by using the ACF approach. Firm level diversity is instrumented by using the predicted level of diversity at the commuting area, where the firm is located. All regressions include the shares of employees belonging to each category considered in the diversity indices; shares of managers and middle-managers; average firm tenure; whether the firm is foreign owned, multi-establishment, and exports; a full set of 2-digit industry, year, size, and county dummies; and industry-year interactions. Standard errors are clustered at the commuting area level. Significance levels: $* * * 1 \%, * * 5 \%$, * $10 \%$. 


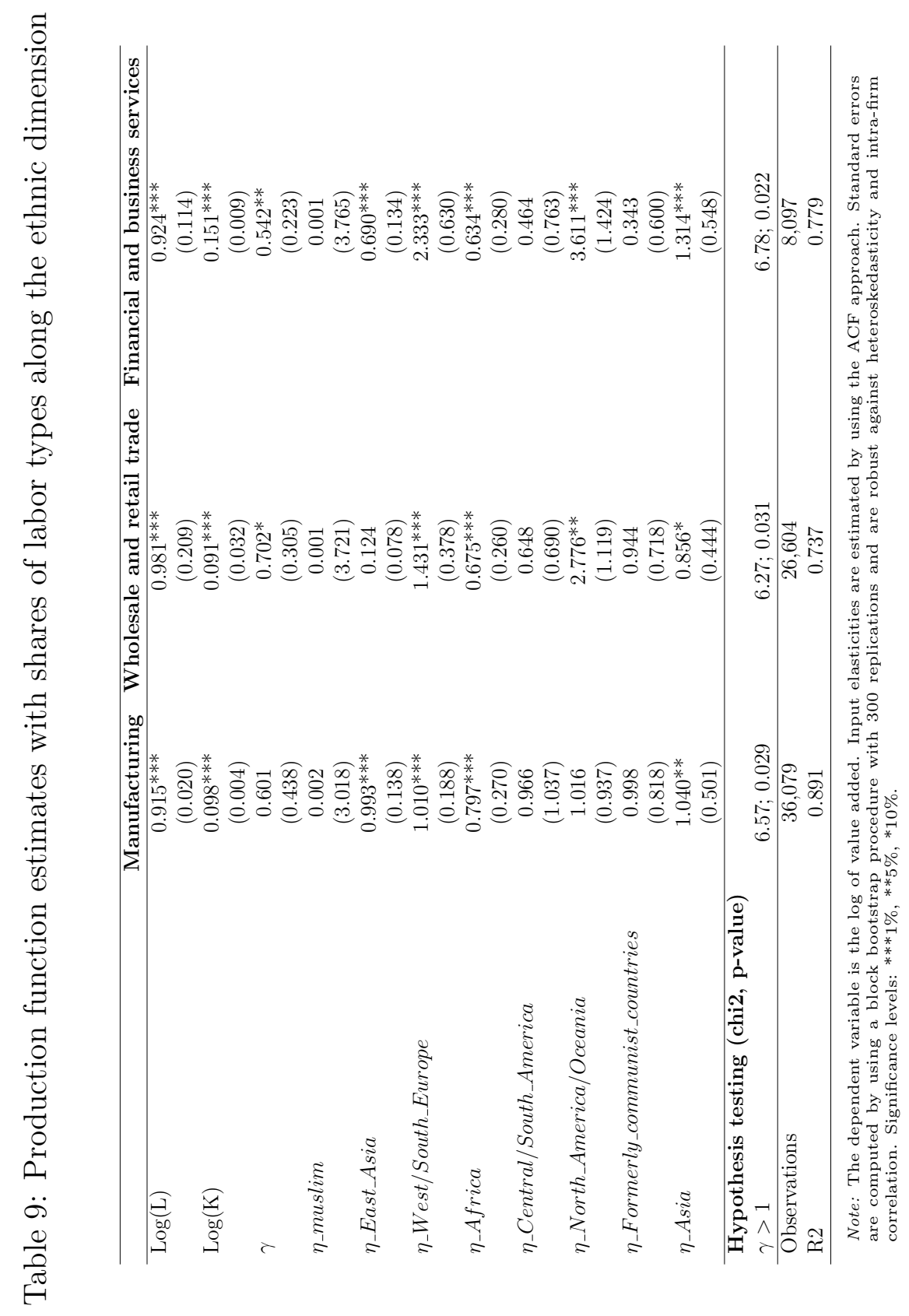




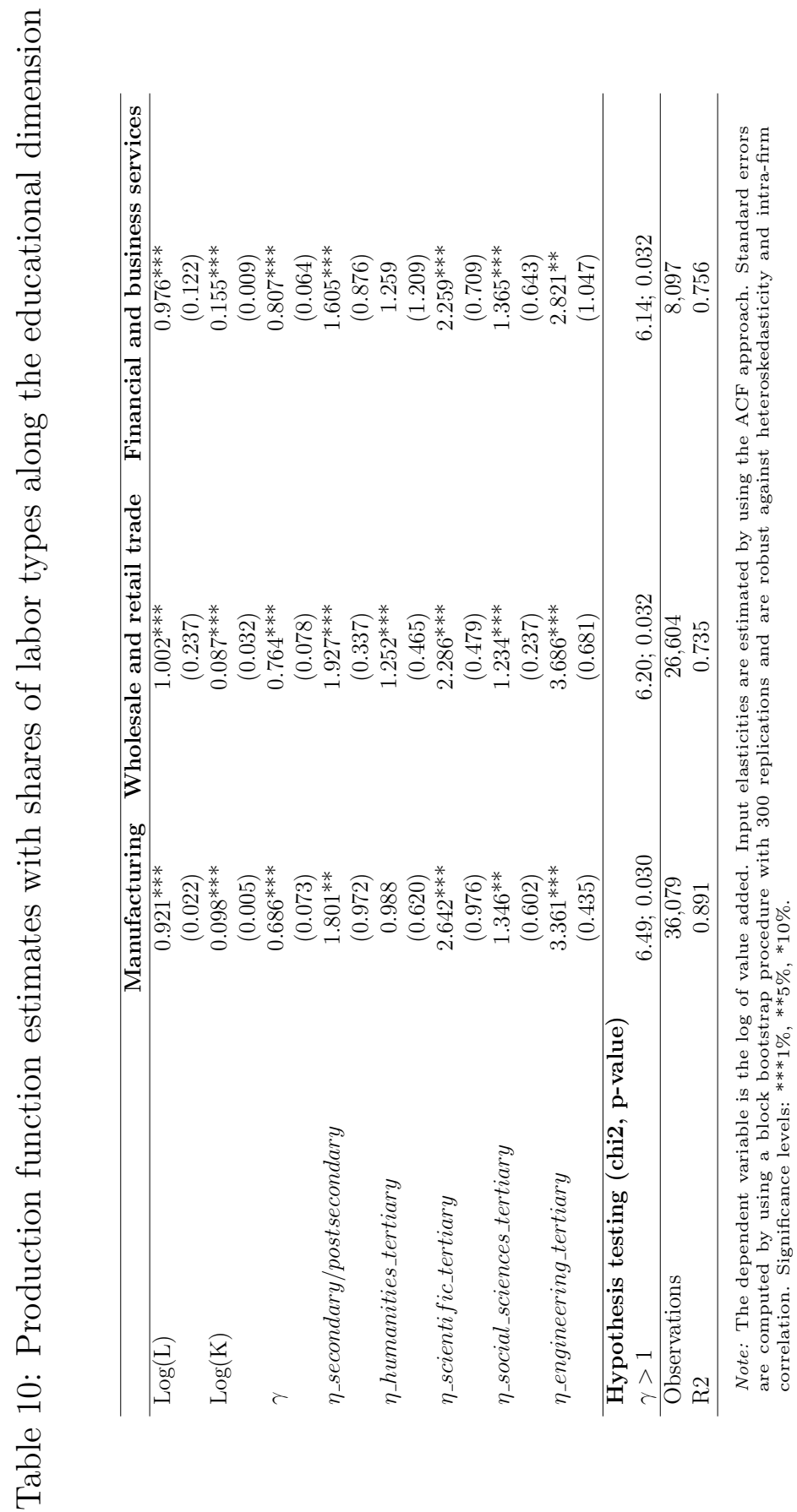




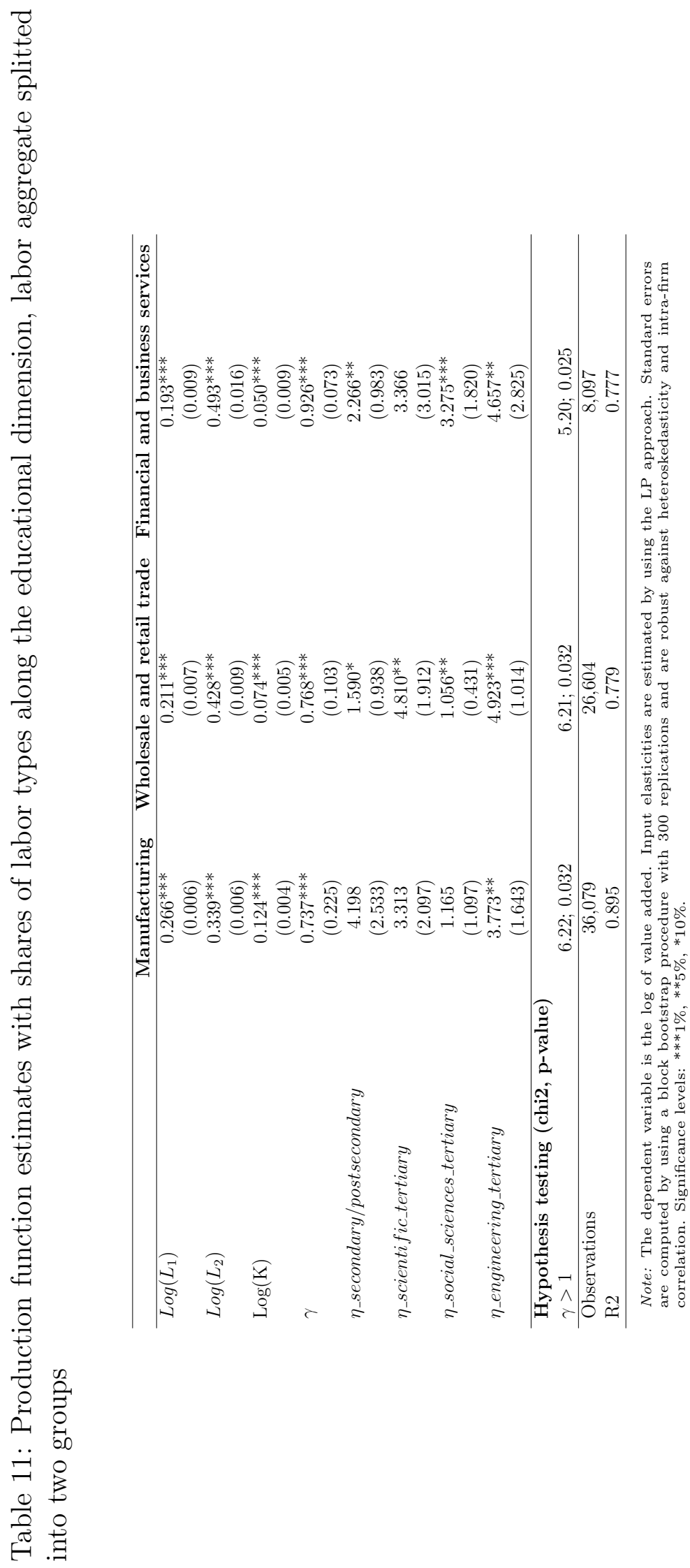




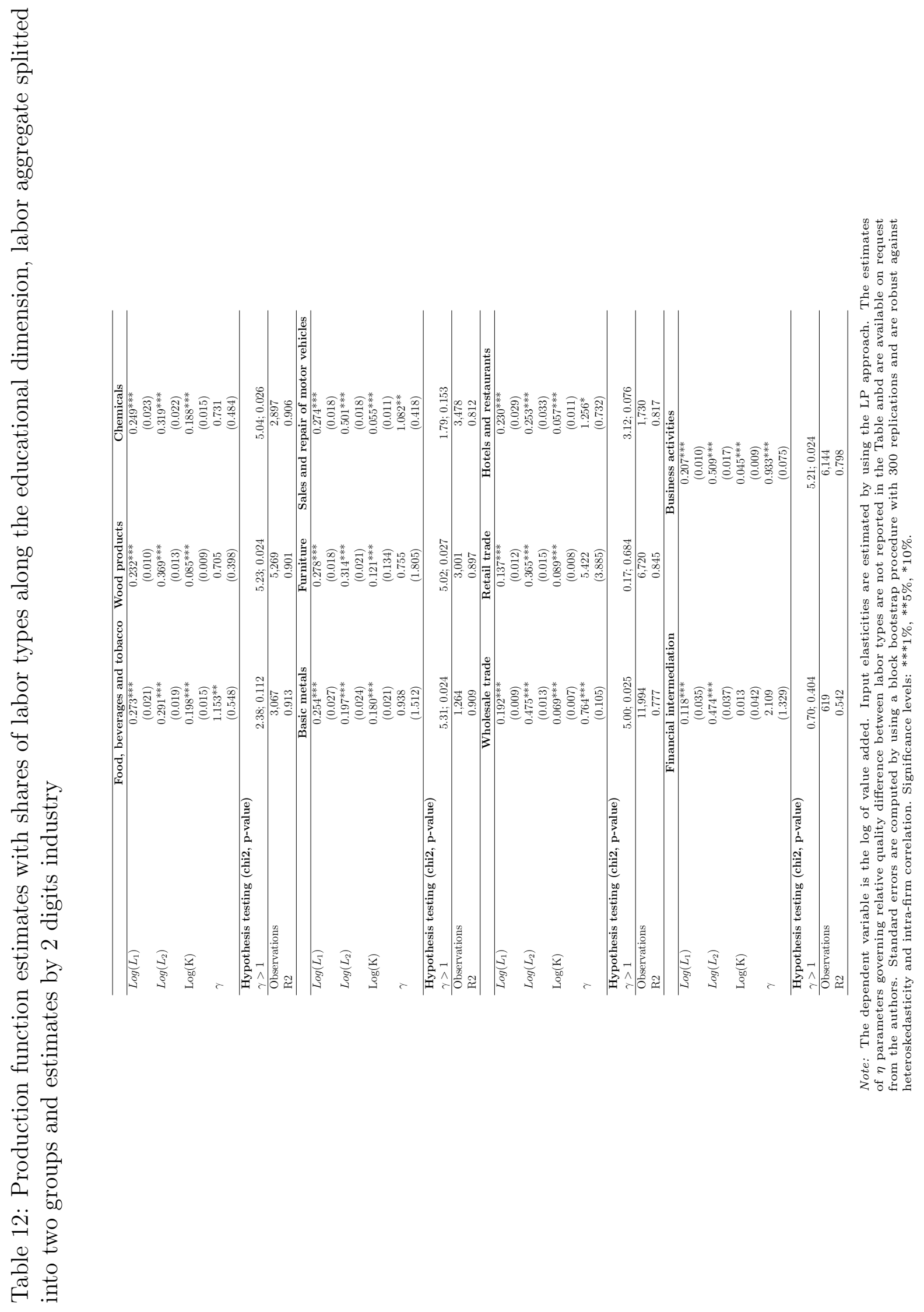


Figure 1: Kernel density of firm TFP, calculated with or without worker heterogeneity in terms of nationality

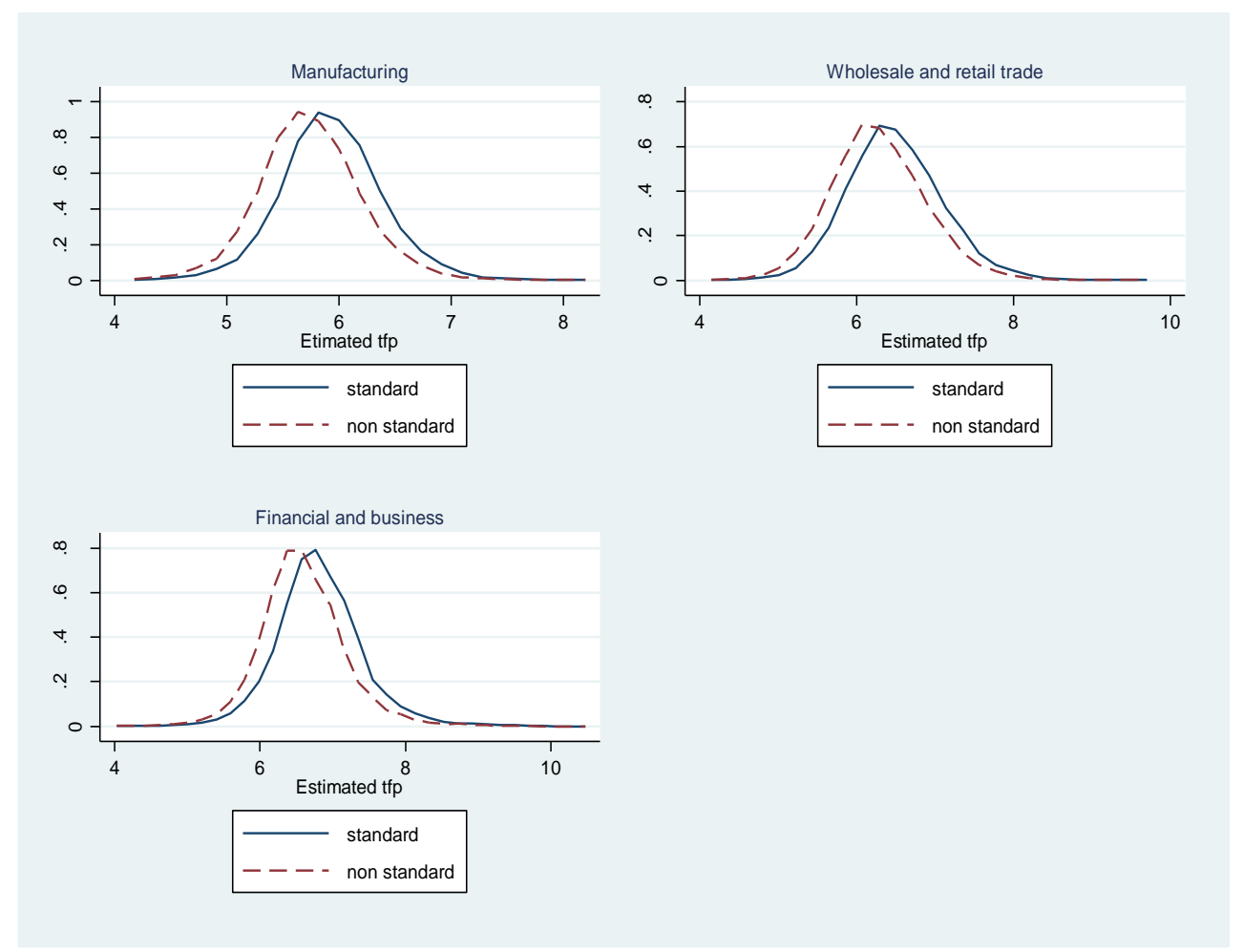

Note: TFP is estimated by using the ACF approach. 
Figure 2: Kernel density of firm TFP, calculated with or without worker heterogeneity in terms of education

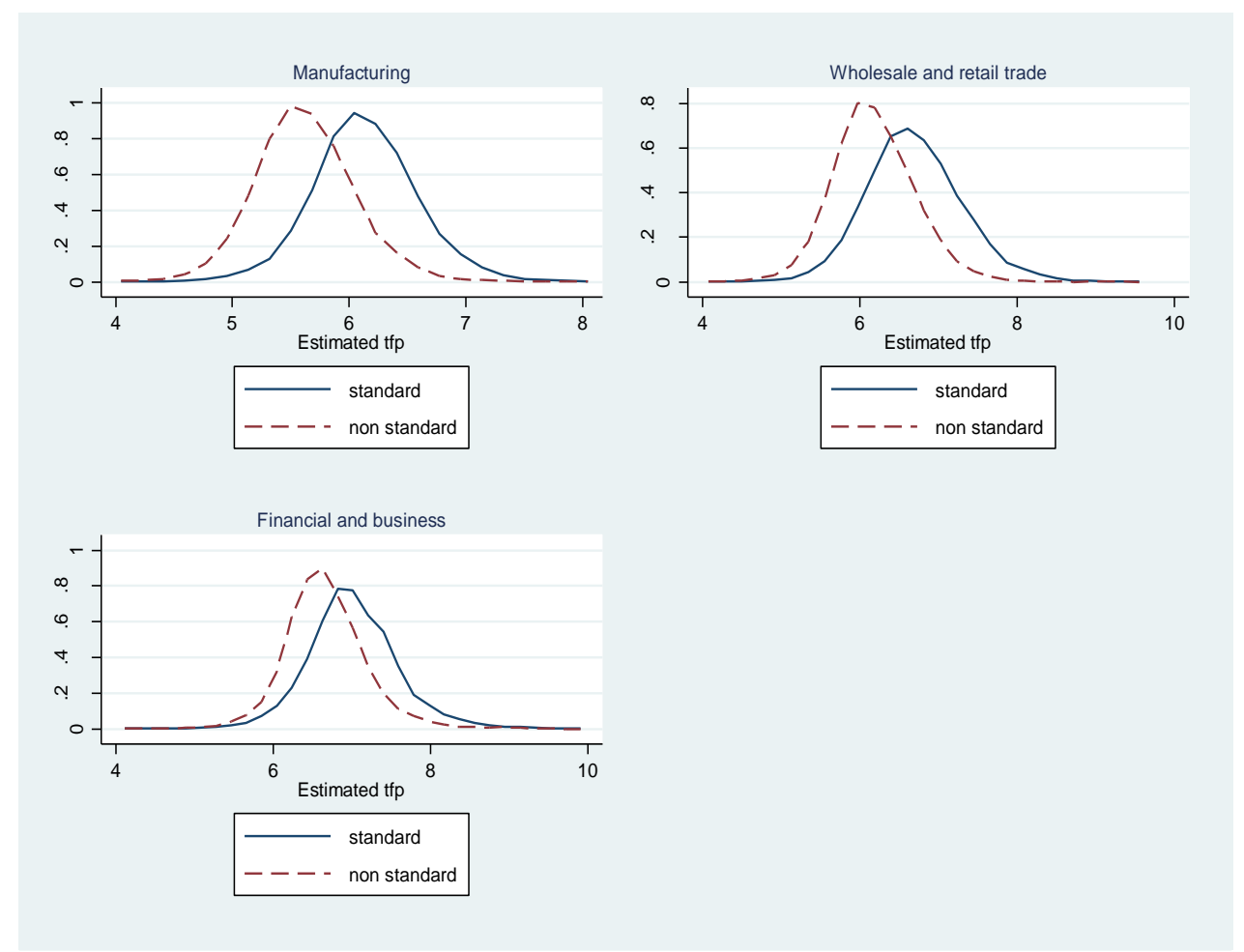

Note: TFP is estimated by using the ACF approach. 


\section{Appendix 1: Groups included in the measure of ethnic diversity}

1) The citizens in the different nationality groups are: Danish: Danish native including second generation immigrants; North America and Oceania: United States, Canada, Australia, New Zealand; Central and South America, Guatemala, Belize, Costa Rica, Honduras, Panama, El Salvador, Nicaragua, Venezuela, Ecuador, Peru, Bolivia, Chile, Argentina, Brazil; Formerly Communist Countries: Armenia, Belarus, Estonia, Georgia, Latvia, Lithuania, Moldova, Russia, Tajikistan, Ukraine, Bulgaria, Czech Republic, Hungary, Poland, Romania, Slovakia, Albania, Bosnia and Herzegovina, Croatia, Rep. of Macedonia, Montenegro, Serbia, and Slovenia; Muslim Countries: Afghanistan, Algeria, Arab Emirates, Azerbaijan, Bahrain, Bangladesh, Brunei Darussalem, Burkina Faso, Camoros, Chad, Djibouti, Egypt, Eritrea, Gambia, Guinea, Indonesia, Iran, Iraq, Jordan, Kazakstan, Kirgizstan, Kuwait, Lebanon, Libyan Arab Jamahiriya, Malaysia, Maldives, Mali, Mauritania, Morocco, Nigeria, Oman, Pakistan, Palestine, Qatar, Saudi Arabia, Senegal, Sierra Leone, Somalia, Sudan, Syria, Tadzhikstan, Tunisia, Turkey, Turkmenistan, Uzbekistan, Yemen; East Asia: China, Hong Kong, Japan, Korea, Korea Dem. People's Rep. Of, Macao, Mongolia, Taiwan; Other Asia: all the other Asian countries non included in both East Asia and Muslim Countries categories and Africa, all the other African countries not included in the Muslim Country; Western and Southern Europe: all the other European countries not included in the Formerly Communist Countries category.

2) The linguistic groups are: Germanic West (Antigua Barbuda, Aruba, Australia, Austria, Bahamas, Barbados, Belgium, Belize, Bermuda, Botswana, Brunei, Cameroon, Canada, Cook Islands, Dominican Republic, Eritrea, Gambia, Germany, Ghana, Grenada, Guyana, Haiti, Ireland, Jamaica, Liberia, Liechtenstein, Luxemburg, Mauritius, Namibia, Netherlands, Netherlands Antilles, New Zealand, Saint Kitts and Nevis, Saint Lucia, Saint Vincent and Grenadines, Seychelles, Sierra Leone, Solomon Islands, South Africa, St. Helena, Suriname, Switzerland, Trinidad and Tobago, Uganda, United Kingdom, United States, Zambia, Zimbabwe); Slavic West (Czech Republic, Poland, Slovakia); Germanic Nord (Denmark, Iceland, Norway, Sweden); FinnoPermic (Finland, Estonia); Romance (Andorra, Angola, Argentina, Benin, Bolivia, Brazil, Burkina Faso, Cape Verde, Chile, Colombia, Costa Rica, Cote D'Ivoire, Cuba, Djibouti, Dominican Republic, Ecuador, El Salvador, Equatorial Guinea, France, French Guyana, Gabon, Guadeloupe, Guatemala, Guinea, Guinea Bissau, Holy See, Honduras, Italy, Macau, Martinique, Mexico, Moldova, Mozambique, Nicaragua, Panama, Peru, Portugal, Puerto Rico, Reunion, Romania, San Marino, Sao Tome, Senegal, Spain, Uruguay, Venezuela); Attic (Cyprus, Greece); Ugric (Hungary); Turkic South (Azerbaijan, Turkey, Turkmenistan); Gheg (Albania, Kosovo, Republic of Macedonia, Montenegro); Semitic Central (Algeria, Bahrain, Comoros, Chad, Egypt, Irak, Israel, Jordan, Kuwait, Lebanon, Lybian Arab Jamahiria, Malta, Mauritiania, Morocco, Oman, Qatar, Saudi Arabia, Sudan, Syrian Arab Republic, Tunisia, Yemen, United Arabs Emirates); Indo-Aryan (Bangladesh, Fiji, India, Maldives, Nepal, Pakistan, Sri Lanka); Slavic South (Bosnia and Herzegovina, Croatia, Serbia, Slovenia); MonKhmer East (Cambodia); Semitic South (Ethiopia); Slavic East (Belarus, Bul- 
garia, Georgia, Mongolia, Russian Federation, Ukraine); Malayo-Polynesian West (Indonesia, Philippines); Malayo-Polynesian Central East (Kiribati, Marshall Islands, Nauru, Samoa, Tonga); Iranian (Afghanistan, Iran, Tajikistan); Betai (Laos, Thailand); Malayic (Malasya); Cushitic East (Somalia); Turkic East (Uzbekistan); Viet-Muong (Vietnam); Volta-Congo (Burundi, Congo, Kenya, Lesotho, Malawi, Nigeria, Rwanda, Swaziland, Tanzania, Togo); Turkic West (Kazakhstan, Kyrgystan); Baltic East (Latvia, Lithuania); Barito (Madagascar); Mande West (Mali); Lolo-Burmese (Burma); Chadic West (Niger); Guarani (Paraguay); Himalayish (Buthan); Armenian (Armenia); Sino Tibetan (China, Hong Kong, Singapore, Taiwan); Japonic (Japan, Republic of Korea, Korea D.P.R.O.). 
Appendix 2: Additional results 


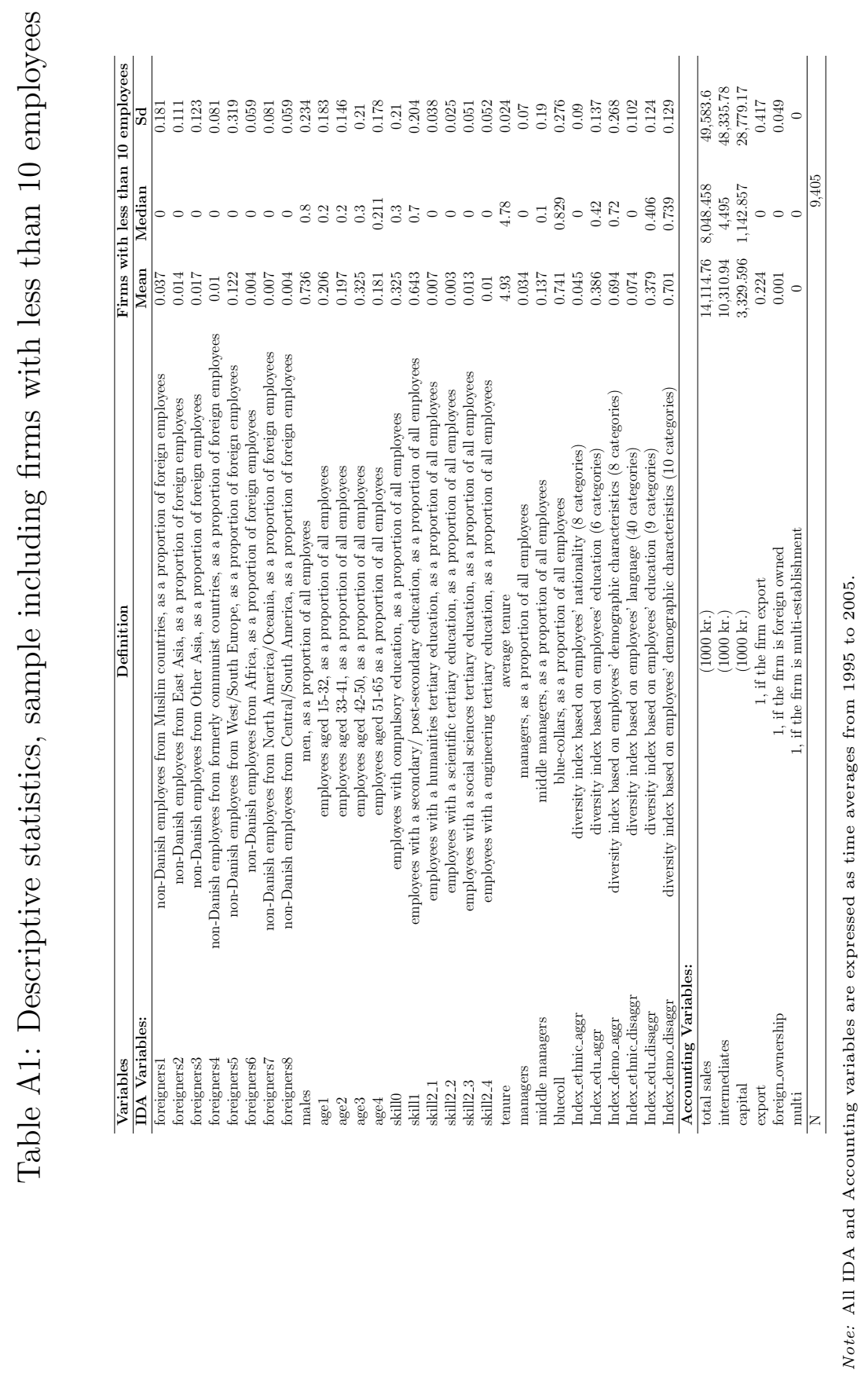

xviii 
Table A2: Labor diversity and firm total factor productivity, sample including firms with fewer than 10 employees

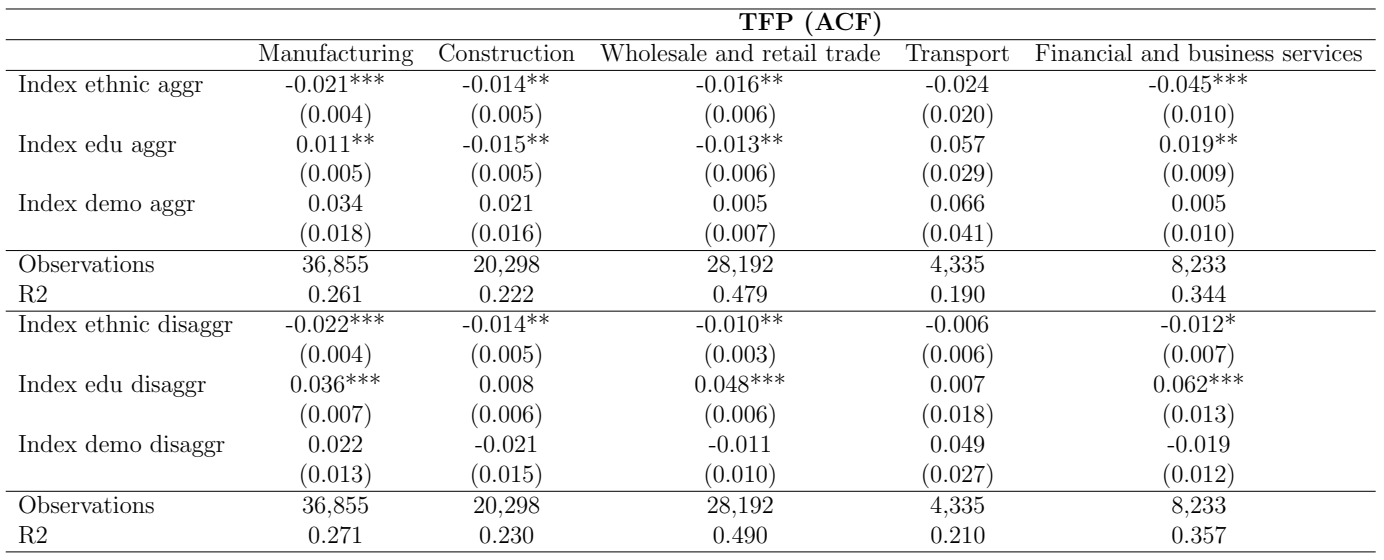

Note: The dependent variable is the log of total factor productivity estimated b using the ACF approach. All regressions include the shares of employees belonging to each category considered in the diversity indices; shares of managers and middle-managers; average firm tenure; whether the firm is foreign owned, multi-establishment, and exports; a full set of 2-digit industry, year, size, and county dummies; and industry-year interactions. Standard errors are clustered at the firm level. Significance levels: $* * * 1 \%, * * 5 \%, * 10 \%$. 
Table A3: Labor diversity and firm exit

\begin{tabular}{|c|c|c|c|c|c|}
\hline & Manufacturing & Construction & Wholesale and retail trade & Transport & Financial and business services \\
\hline \multirow{2}{*}{ Index ethnic aggr } & 0.001 & -0.006 & $-0.007^{*}$ & -0.010 & -0.008 \\
\hline & $(0.003)$ & $(0.004)$ & $(0.003)$ & $(0.012)$ & $(0.006)$ \\
\hline \multirow[t]{2}{*}{ Index edu aggr } & -0.004 & -0.014 & $-0.008^{*}$ & -0.009 & 0.003 \\
\hline & $(0.004)$ & $(0.009)$ & $(0.004)$ & $(0.007)$ & $(0.003)$ \\
\hline \multirow[t]{2}{*}{ Index demo aggr } & $-0.011^{*}$ & $-0.025^{*}$ & -0.016 & -0.009 & -0.022 \\
\hline & $(0.006)$ & $(0.013)$ & $(0.009)$ & $(0.007)$ & $(0.014)$ \\
\hline Observations & 35,887 & 18,024 & 26,418 & 4,007 & 7,931 \\
\hline $\mathrm{R} 2$ & 0.034 & 0.04 & 0.047 & 0.055 & 0.065 \\
\hline \multirow{2}{*}{ Index ethnic disaggr } & -0.002 & -0.006 & -0.002 & -0.012 & -0.002 \\
\hline & $(0.003)$ & $(0.004)$ & $(0.001)$ & $(0.008)$ & $(0.002)$ \\
\hline \multirow[t]{2}{*}{ Index edu disaggr } & -0.003 & -0.012 & -0.004 & -0.003 & 0.002 \\
\hline & $(0.003)$ & $(0.008)$ & $(0.003)$ & $(0.010)$ & $(0.003)$ \\
\hline \multirow[t]{2}{*}{ Index demo disaggr } & $-0.010^{*}$ & $-0.024^{* *}$ & -0.016 & -0.011 & -0.023 \\
\hline & $(0.006)$ & $(0.012)$ & $(0.008)$ & $(0.008)$ & $(0.017)$ \\
\hline Observations & 48,238 & 26,969 & 41,493 & 6,287 & 14,008 \\
\hline $\mathrm{R} 2$ & 0.035 & 0.042 & 0.048 & 0.057 & 0.068 \\
\hline
\end{tabular}

Note: The dependent variable is a dummy variable equal to 1 if the firm exits the market. All regressions include the shares of employees belonging to each category considered in the diversity indices; shares of managers and middle-managers; average firm tenure; whether the firm is foreign owned, multi-establishment, and exports; a full set of 2-digit industry, year, size, and county dummies; and whether the firm is foreign owned, multi-establishment, and exports; a full set of 2-digit industry, year, size, and co 


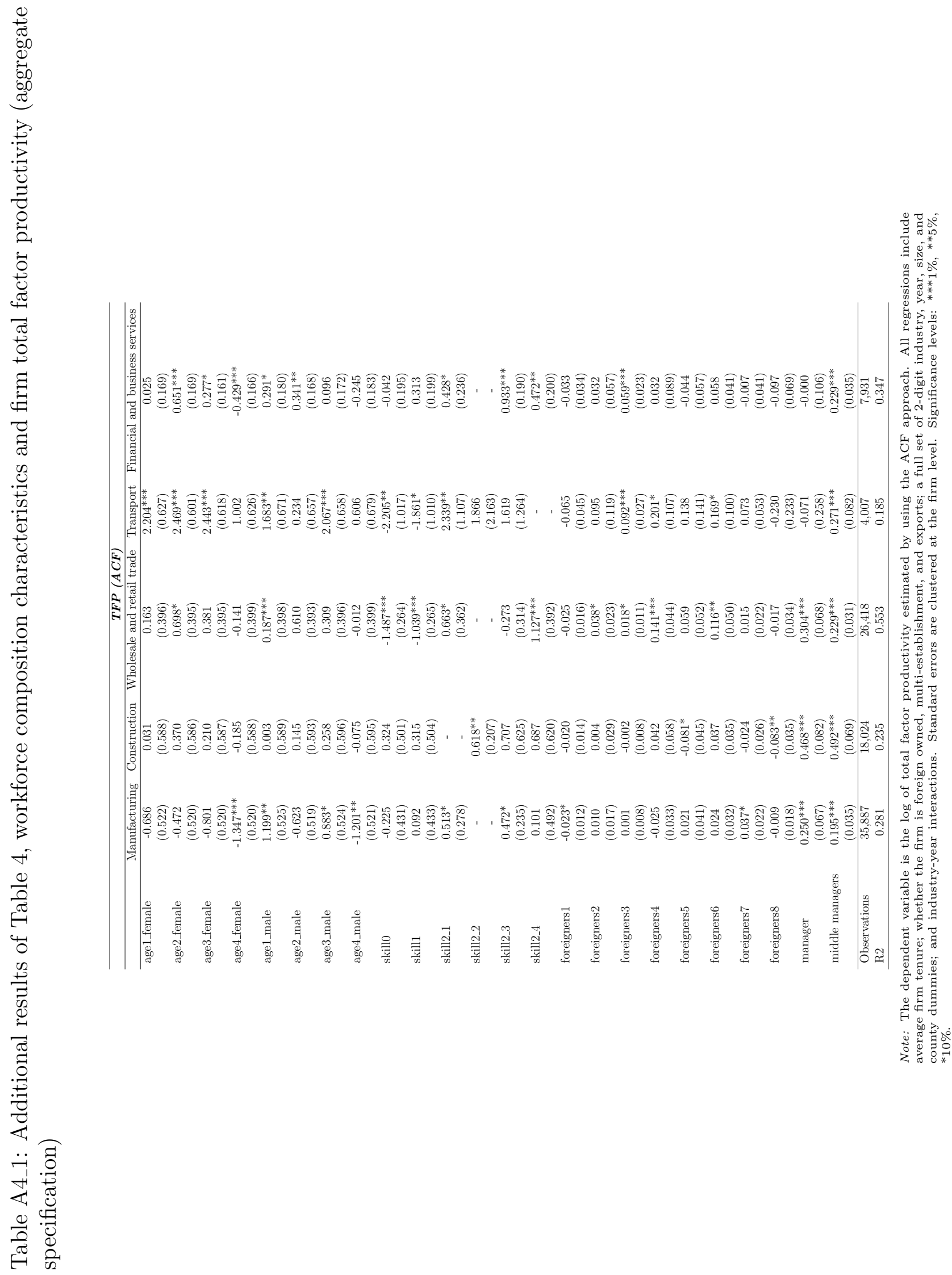




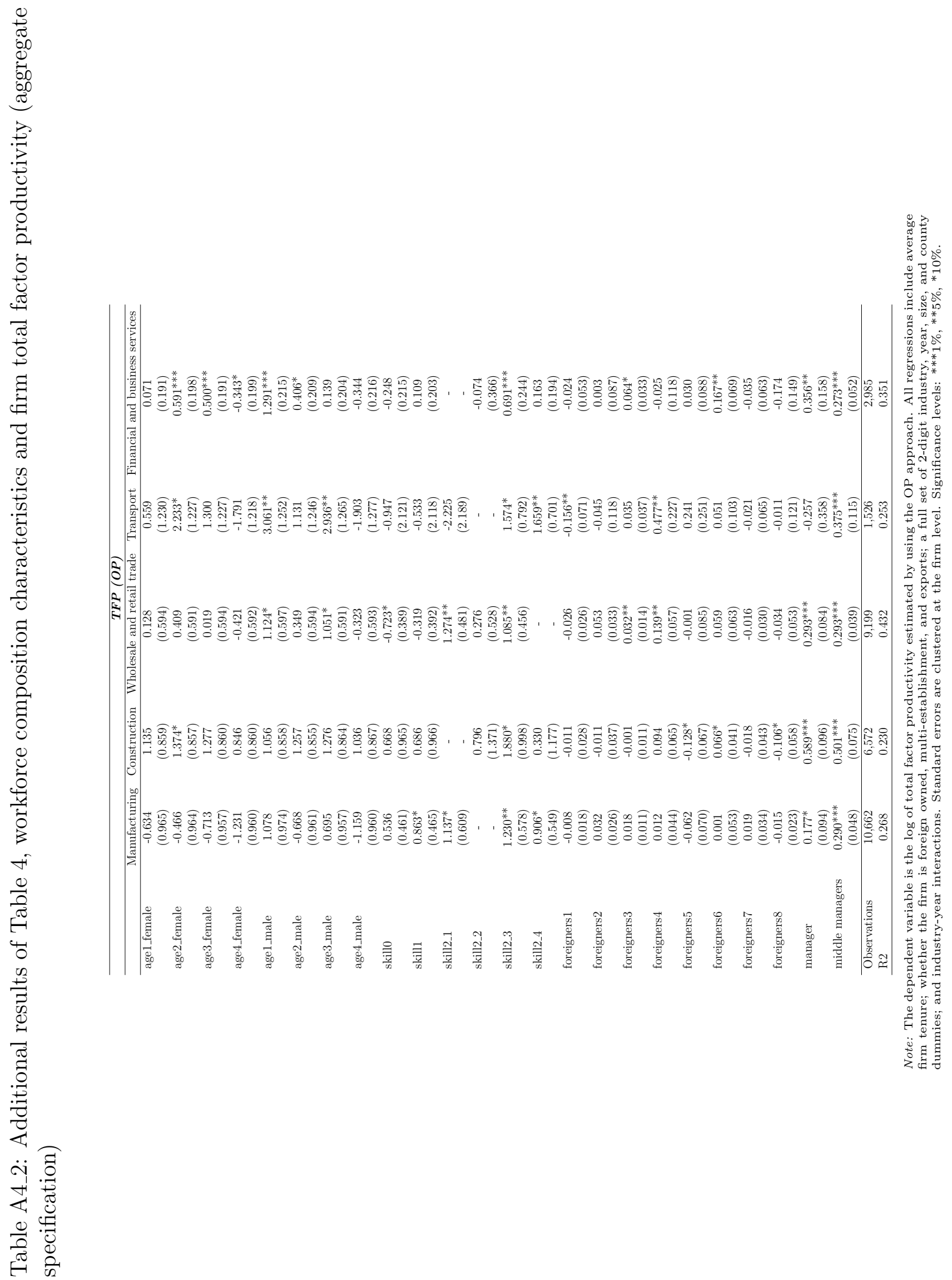




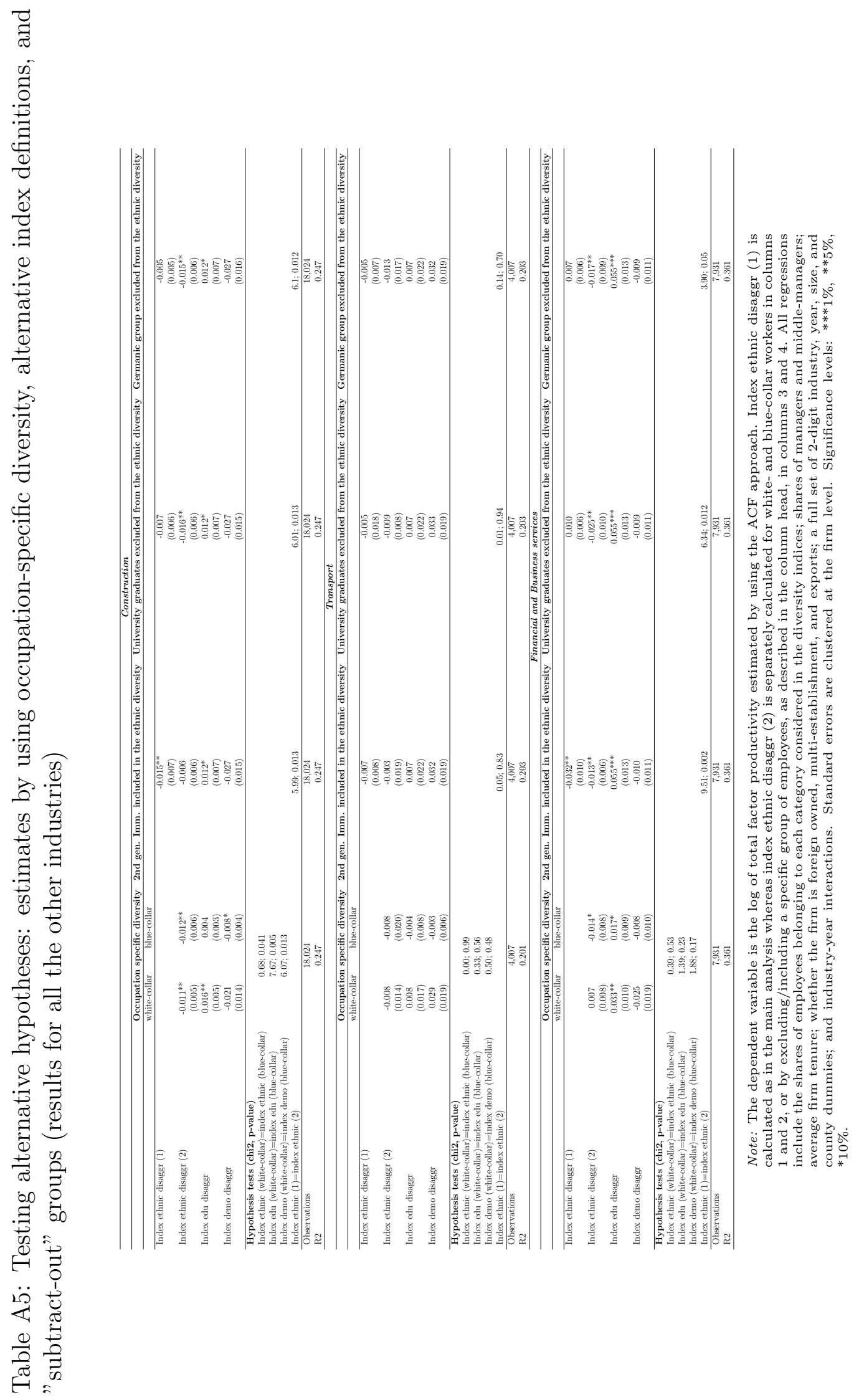

xxiv 


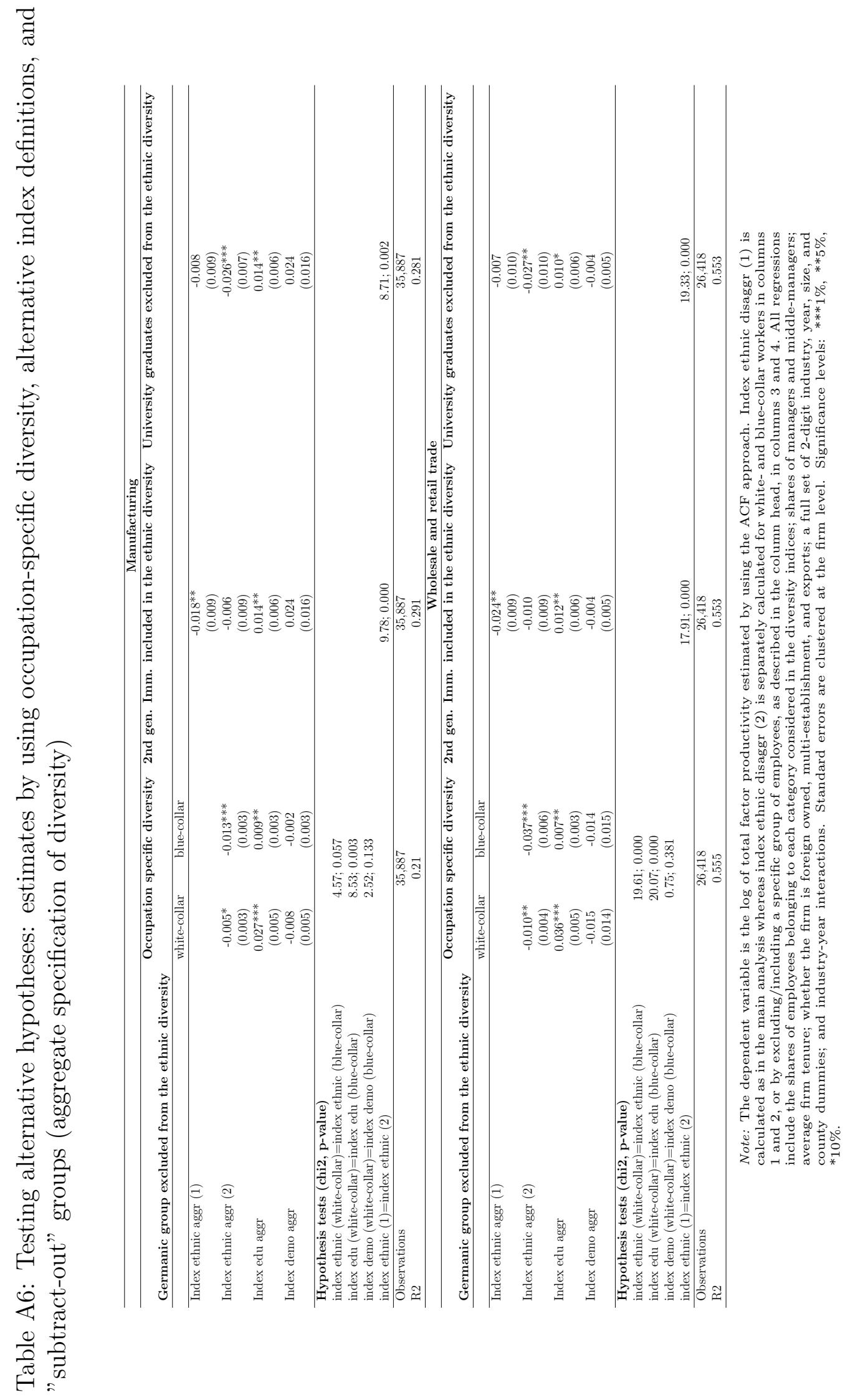




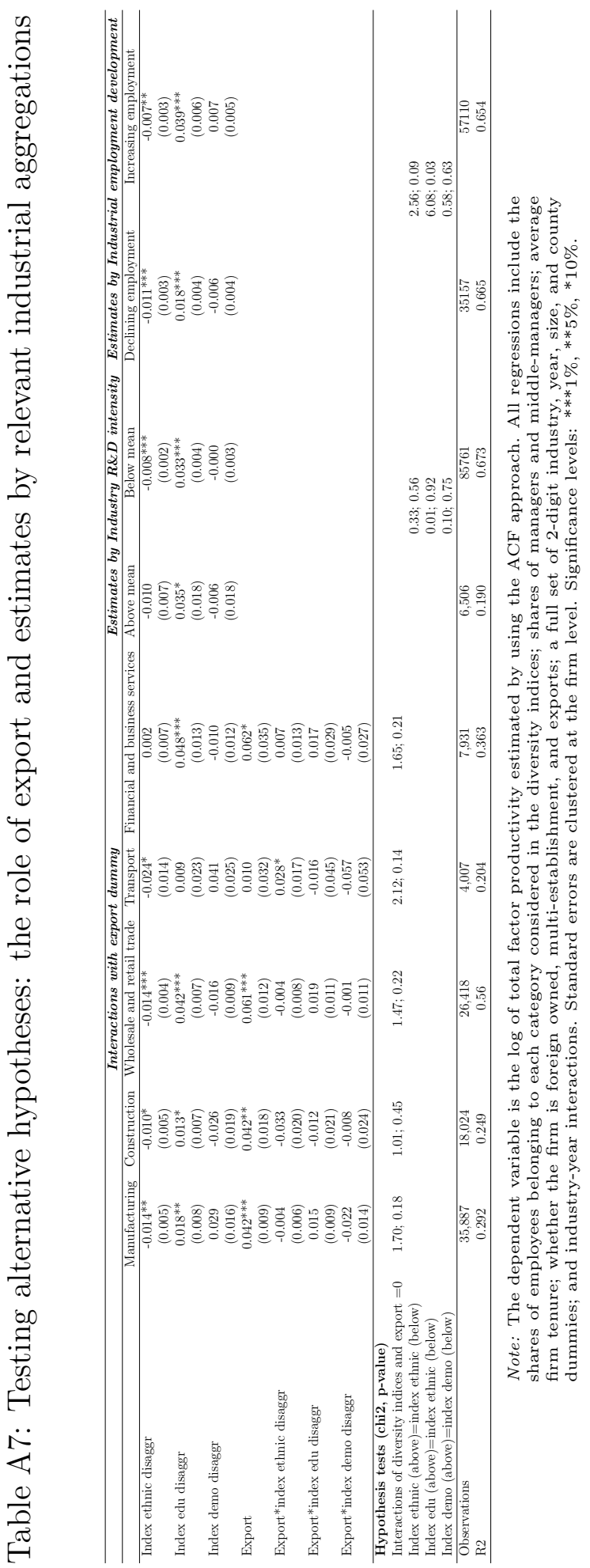

xxvi 


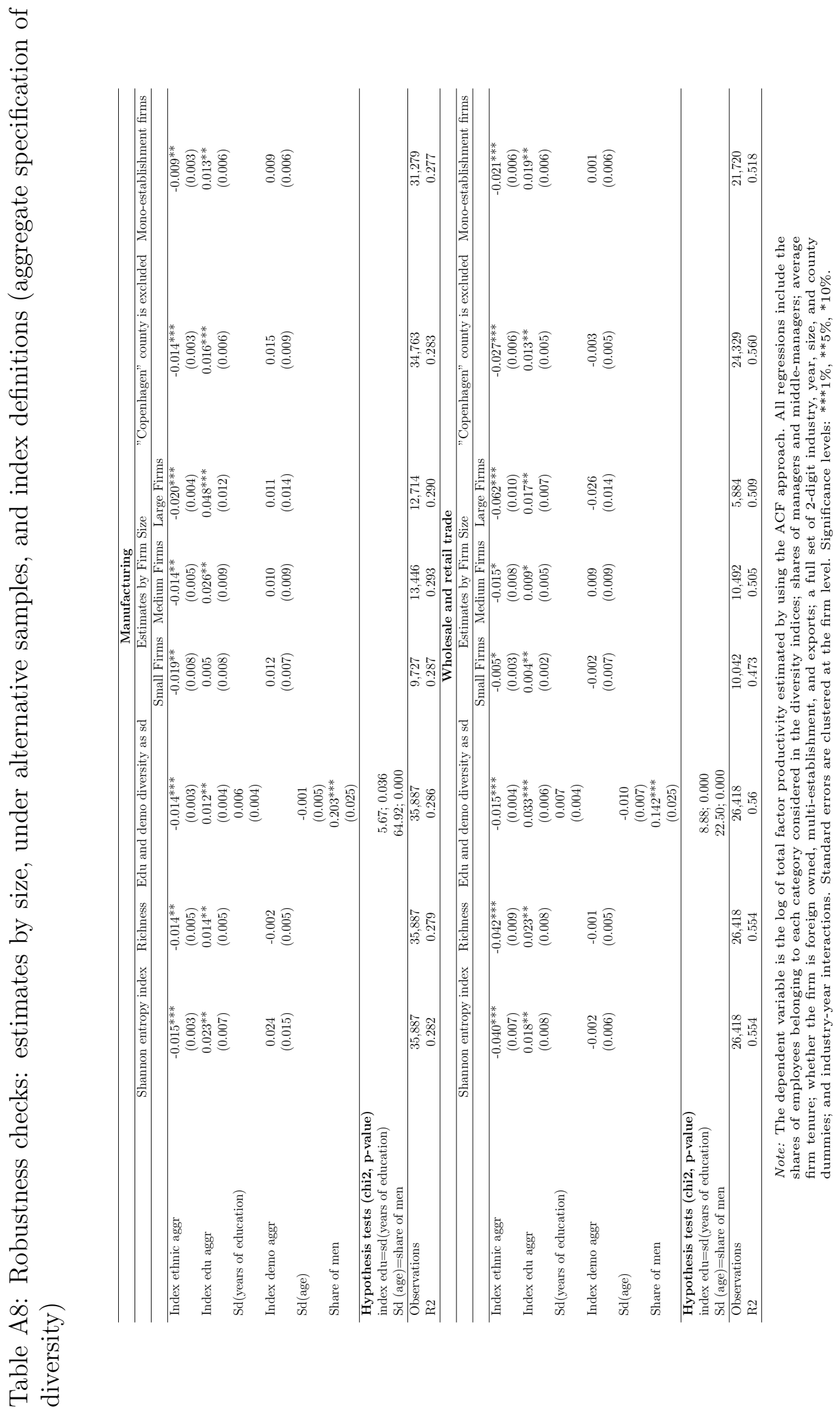

xxvii 
Table A9: Labor diversity and productivity, IV results: additional second stage regressions

\begin{tabular}{|c|c|c|c|c|c|}
\hline & Manufacturing & Construction & Wholesale and retail trade & Transport & Financial and business services \\
\hline & \multicolumn{5}{|c|}{ All sample } \\
\hline \multirow[t]{2}{*}{ index ethnic disaggr } & $-0.026^{*}$ & $-0.038^{*}$ & $-0.028^{* *}$ & -0.031 & 0.009 \\
\hline & $(0.014)$ & $(0.019)$ & $(0.014)$ & $(0.084)$ & $(0.012)$ \\
\hline \multirow[t]{2}{*}{ index edu disaggr } & $0.061^{* *}$ & 0.037 & $0.095^{* *}$ & 0.047 & $0.078^{*}$ \\
\hline & $(0.028)$ & $(0.019)$ & $(0.040)$ & $(0.149)$ & $(0.038)$ \\
\hline \multirow[t]{2}{*}{ index demo disaggr } & 0.093 & -0.048 & -0.056 & -0.085 & -0.048 \\
\hline & $(0.086)$ & $(0.049)$ & $(0.033)$ & $(0.070)$ & $(0.033)$ \\
\hline Observations & 35,887 & 18,024 & 26,418 & 4,007 & 7,931 \\
\hline \multirow[t]{2}{*}{$\mathrm{R} 2$} & 0.310 & 0.123 & 0.252 & 0.189 & 0.200 \\
\hline & \multicolumn{5}{|c|}{ Mono-establishment firms } \\
\hline \multirow[t]{2}{*}{ index ethnic disaggr } & -0.017 & -0.062 & -0.024 & - & 0.017 \\
\hline & $(0.093)$ & $(0.035)$ & $(0.016)$ & - & $(0.079)$ \\
\hline \multirow[t]{2}{*}{ index edu disaggr } & $0.057^{*}$ & 0.028 & $0.082^{* *}$ & - & 0.074 \\
\hline & $(0.029)$ & $(0.021)$ & $(0.061)$ & - & $(0.037)$ \\
\hline \multirow[t]{2}{*}{ index demo disaggr } & 0.143 & -0.046 & -0.027 & - & -0.066 \\
\hline & $(0.088)$ & $(0.085)$ & $(0.033)$ & - & $(0.157)$ \\
\hline Observations & 31,279 & 17,118 & 21,720 & - & 6,479 \\
\hline \multirow[t]{2}{*}{$\mathrm{R} 2$} & 0.260 & 0.108 & 0.277 & - & 0.114 \\
\hline & \multicolumn{5}{|c|}{ Small firms with fewer than 50 employees } \\
\hline \multirow[t]{2}{*}{ index ethnic disaggr } & $-0.015^{*}$ & -0.075 & $-0.033^{* *}$ & - & 0.027 \\
\hline & $(0.008)$ & $(0.049)$ & $(0.014)$ & - & $(0.019)$ \\
\hline \multirow[t]{2}{*}{ index edu disaggr } & $0.032^{*}$ & 0.055 & $0.123^{*}$ & - & 0.082 \\
\hline & $(0.017)$ & $(0.037)$ & $(0.069)$ & - & $(0.049)$ \\
\hline \multirow[t]{2}{*}{ index demo disaggr } & 0.170 & -0.084 & -0.055 & - & -0.041 \\
\hline & $(0.161)$ & $(0.079)$ & $(0.046)$ & - & $(0.035)$ \\
\hline Observations & 23,173 & 15,423 & 20,534 & - & 5,536 \\
\hline \multirow[t]{2}{*}{$\mathrm{R} 2$} & 0.435 & 0.096 & 0.188 & - & 0.109 \\
\hline & \multicolumn{5}{|c|}{ Copenhagen county is excluded } \\
\hline \multirow[t]{2}{*}{ index ethnic disaggr } & -0.034 & -0.047 & -0.013 & -0.027 & 0.025 \\
\hline & $(0.023)$ & $(0.030)$ & $(0.016)$ & $(0.068)$ & $(0.012)$ \\
\hline \multirow[t]{2}{*}{ index edu disaggr } & $0.053^{* *}$ & $0.025^{*}$ & $0.060^{* *}$ & 0.022 & $0.080^{*}$ \\
\hline & $(0.022)$ & $(0.013)$ & $(0.021)$ & $(0.123)$ & $(0.042)$ \\
\hline \multirow[t]{2}{*}{ index demo disaggr } & 0.144 & $-0.057^{*}$ & -0.028 & -0.127 & -0.102 \\
\hline & $(0.213)$ & $(0.029)$ & $(0.041)$ & $(0.099)$ & $(0.094)$ \\
\hline Observations & 34,763 & 17,302 & 24,329 & 3,619 & 6,149 \\
\hline \multirow[t]{2}{*}{$\mathrm{R} 2$} & 0.263 & 0.145 & 0.365 & 0.128 & 0.255 \\
\hline & \multicolumn{5}{|c|}{ Firms established before 1990} \\
\hline \multirow[t]{2}{*}{ index ethnic disaggr } & -0.038 & - & $-0.045^{* *}$ & - & 0.016 \\
\hline & $(0.084)$ & - & $(0.022)$ & - & $(0.014)$ \\
\hline \multirow[t]{2}{*}{ index edu disaggr } & $0.023^{*}$ & - & 0.186 & - & 0.142 \\
\hline & $(0.014)$ & - & $(0.269)$ & - & $(0.089)$ \\
\hline index demo disaggr & 0.105 & - & -0.107 & - & -0.029 \\
\hline & $(0.180)$ & - & $(0.139)$ & - & $(0.142)$ \\
\hline Observations & 8,962 & - & 5,447 & - & 1,717 \\
\hline $\mathrm{R} 2$ & 0.231 & - & 0.281 & - & 0.198 \\
\hline
\end{tabular}

Note: The dependent variable is the log of total factor productivity estimated by using the ACF approach. Firm level diversity is instrumented by using the predicted level of diversity at the commuting area, where the firm is located. All regressions include the shares of emp firm tenure; whether the firm is foreign owned, multi-establishment, and exports; a full set of 2 -digit industry,
dummies. Standard errors are clustered at the commuting area level. Significance levels: ***1\%,**5\%,*10\%. 
Table A10: IV results: first stage regressions (aggregate specification of diversity)

\begin{tabular}{|c|c|c|c|}
\hline & \multicolumn{3}{|c|}{ Manufacturing } \\
\hline & Index ethnic aggr & Index edu aggr & Index demo aggr \\
\hline \multirow[t]{2}{*}{ index ethnic com } & $0.949^{* * *}$ & -0.064 & $-0.060^{* *}$ \\
\hline & $(0.080)$ & $(0.045)$ & $(0.027)$ \\
\hline \multirow[t]{2}{*}{ index edu com } & $-0.348^{* *}$ & $0.072^{* * *}$ & $-0.172^{* * *}$ \\
\hline & $(0.110)$ & $(0.028)$ & $(0.041)$ \\
\hline \multirow[t]{2}{*}{ index demo com } & $-1.181^{* * *}$ & 0.024 & $1.054^{* * *}$ \\
\hline & $(0.246)$ & $(0.182)$ & $(0.093)$ \\
\hline F test (excluded instruments); $\mathrm{p}$-value & $48.51 ; 0.000$ & $11.67 ; 0.000$ & $30.61 ; 0.000$ \\
\hline Observations & 48,238 & 48,238 & 48,238 \\
\hline \multirow[t]{3}{*}{$\mathrm{R} 2$} & 0.404 & 0.462 & 0.371 \\
\hline & \multicolumn{3}{|c|}{ Construction } \\
\hline & Index ethnic aggr & Index edu aggr & Index demo aggr \\
\hline \multirow[t]{2}{*}{ index ethnic com } & $0.247^{* * *}$ & $-0.301^{* * *}$ & -0.041 \\
\hline & $(0.063)$ & $(0.062)$ & $(0.032)$ \\
\hline \multirow[t]{2}{*}{ index edu com } & 0.079 & $0.241^{* *}$ & -0.076 \\
\hline & $(0.051)$ & $(0.092)$ & $(0.061)$ \\
\hline \multirow[t]{2}{*}{ index demo com } & -0.119 & $0.685^{* * *}$ & $0.590^{* * *}$ \\
\hline & $(0.252)$ & $(0.173)$ & $(0.140)$ \\
\hline F test (excluded instruments); $\mathrm{p}$-value & $9.19 ; 0.000$ & $7.93 ; 0.003$ & $7.12 ; 0.004$ \\
\hline Observations & 26,969 & 26,969 & 26,969 \\
\hline \multirow[t]{3}{*}{$\mathrm{R} 2$} & 0.223 & 0.513 & 0.397 \\
\hline & \multicolumn{3}{|c|}{ Wholesale and retail trade } \\
\hline & Index ethnic aggr & Index edu aggr & Index demo aggr \\
\hline \multirow[t]{2}{*}{ index ethnic com } & $0.463^{* * *}$ & $-0.411^{* * *}$ & $0.234^{* * *}$ \\
\hline & $(0.099)$ & $(0.050)$ & $(0.049)$ \\
\hline \multirow[t]{2}{*}{ index edu com } & 0.101 & $0.902^{* * *}$ & $-0.655^{* * *}$ \\
\hline & $(0.190)$ & $(0.092)$ & $(0.058)$ \\
\hline \multirow[t]{2}{*}{ index demo com } & $0.147^{*}$ & $-0.281^{* * *}$ & $1.392^{* * *}$ \\
\hline & $(0.086)$ & $(0.079)$ & $(0.096)$ \\
\hline F test (excluded instruments); p-value & $30.82 ; 0.000$ & $28.42 ; 0.000$ & $81.58 ; 0.000$ \\
\hline Observations & 41,493 & 41,493 & 41,493 \\
\hline \multirow[t]{3}{*}{$\mathrm{R} 2$} & 0.331 & 0.487 & 0.47 \\
\hline & & Transport & \\
\hline & Index ethnic aggr & Index edu aggr & Index demo aggr \\
\hline \multirow[t]{2}{*}{ index ethnic com } & $0.407^{* * *}$ & 0.157 & $-0.168^{* *}$ \\
\hline & $(0.106)$ & $(0.239)$ & $(0.067)$ \\
\hline \multirow[t]{2}{*}{ index edu com } & 0.060 & $0.507^{* *}$ & 0.155 \\
\hline & $(0.166)$ & $(0.231)$ & $(0.145)$ \\
\hline \multirow[t]{2}{*}{ index demo com } & $-1.030^{* *}$ & 0.135 & $0.589^{* *}$ \\
\hline & $(0.326)$ & $(0.249)$ & $(0.188)$ \\
\hline F test (excluded instruments); p-value & $11.97 ; 0.000$ & $6.94 ; 0.000$ & $9.48 ; 0.000$ \\
\hline Observations & 6,285 & 6,285 & 6,285 \\
\hline \multirow[t]{3}{*}{$\mathrm{R} 2$} & 0.393 & 0.327 & 0.294 \\
\hline & \multicolumn{3}{|c|}{ Financial and business services } \\
\hline & Index ethnic aggr & Index edu aggr & Index demo aggr \\
\hline index ethnic com & $0.678^{* * *}$ & -0.037 & $-0.139^{* *}$ \\
\hline & $(0.186)$ & $(0.093)$ & $(0.060)$ \\
\hline index edu com & -0.041 & $0.297^{* * *}$ & 0.070 \\
\hline & $(0.133)$ & $(0.086)$ & $(0.072)$ \\
\hline index demo com & -0.018 & $-0.336^{*}$ & $1.004^{* * *}$ \\
\hline & $(0.157)$ & $(0.183)$ & $(0.111)$ \\
\hline F test (excluded instruments); p-value & $10.35 ; 0.000$ & $5.12 ; 0.002$ & $51.19 ; 0.000$ \\
\hline Observations & 14,008 & 14,008 & 14,008 \\
\hline $\mathrm{R} 2$ & 0.43 & 0.593 & 0.441 \\
\hline
\end{tabular}

Note: The dependent variable is diversity at the firm level. All regressions include the shares of employees belonging to each category considered in the diversity indices; shares of managers and middle-managers; average firm tenure; whether the firm is foreign owned, multi-establishment, and exports; a full set of 2-digit industry, year, size, and county dummies; and industry-year interactions. Standard errors are clustered at the commuting area level. Significance levels: ***1\%, **5\%, *10\%. 


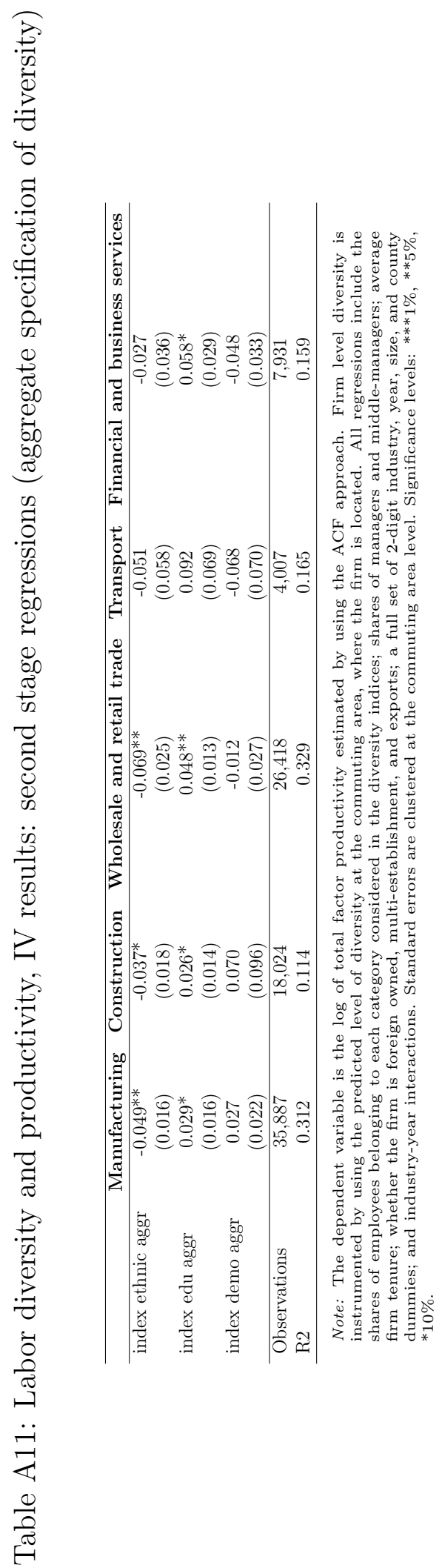

